OPEN ACCESS

Edited by:

Rosa M. Rivero,

Center for Edaphology and Applied

Biology of Segura, Spanish National

Research Council (CSIC), Spain

Reviewed by:

Anshika Narang,

Rutgers University, Newark,

United States

Alexandro Cagliari,

Universidade Estadual do Rio Grande

do Sul, Brazil

*Correspondence:

Liqun Zhao

zhaolq70@163.com

orcid.org/0000-0001-6718-8130

tThese authors have contributed

equally to this work

Specialty section:

This article was submitted to

Plant Abiotic Stress,

a section of the journal

Frontiers in Plant Science

Received: 12 May 2021

Accepted: 22 June 2021

Published: 14 July 2021

Citation:

Wang W, Zhang J, Ai L, Wu D, Li B,

Zhang $L$ and Zhao $L$ (2021) Cyclic

Nucleotide-Gated lon Channel 6

Mediates Thermotolerance in

Arabidopsis Seedlings by Regulating

Hydrogen Peroxide Production via

Cytosolic Calcium lons.

Front. Plant Sci. 12:708672.

doi: 10.3389/fpls.2021.708672

\section{Cyclic Nucleotide-Gated Ion Channel 6 Mediates Thermotolerance in Arabidopsis Seedlings by Regulating Hydrogen Peroxide Production via Cytosolic Calcium Ions}

\author{
Wenxu Wang ${ }^{1 \dagger}$, Jiaojiao Zhang ${ }^{1 \dagger}$, Lijuan $\mathrm{Ai}^{1}$, Dan Wu' ${ }^{1}$, Bing $\mathrm{Li}^{1}$, Lingang Zhang ${ }^{2}$ and \\ Liqun Zhao ${ }^{1 *}$
}

\begin{abstract}
${ }^{1}$ Hebei Key Laboratory of Molecular and Cellular Biology, Key Laboratory of Molecular and Cellular Biology of the Ministry of Education, Hebei Collaboration Innovation Center for Cell Signaling, College of Life Sciences, Hebei Normal University, Shijiazhuang, China, ${ }^{2}$ College of Life Sciences, Inner Mongolia University, Hohhot, China
\end{abstract}

We previously reported the involvement of cyclic nucleotide-gated ion channel 6 (CNGC6) and hydrogen peroxide $\left(\mathrm{H}_{2} \mathrm{O}_{2}\right)$ in plant responses to heat shock $(\mathrm{HS})$. To demonstrate their relationship with plant thermotolerance, we assessed the effect of HS on several groups of Arabidopsis (Arabidopsis thaliana) seedlings: wild-type, cngc6 mutant, and its complementation line. Under exposure to $\mathrm{HS}$, the level of $\mathrm{H}_{2} \mathrm{O}_{2}$ was lower in the cngc6 mutant seedlings than in the wild-type (WT) seedlings but obviously increased in the complementation line. The treatment of Arabidopsis seeds with calcium ions $\left(\mathrm{Ca}^{2+}\right)$ increased the $\mathrm{H}_{2} \mathrm{O}_{2}$ levels in the seedlings under $\mathrm{HS}$ treatment, whereas treatment with a $\mathrm{Ca}^{2+}$ chelator (EGTA) inhibited it, indicating that CNGC6 may stimulate the accumulation of $\mathrm{H}_{2} \mathrm{O}_{2}$ in a manner dependent on an increase in cytosolic $\mathrm{Ca}^{2+}\left(\left[\mathrm{Ca}^{2+}\right]_{\mathrm{cyt}}\right)$. This point was verified by phenotypic observations and thermotolerance testing with transgenic plants overexpressing AtRbohB and AtRbohD (two genes involved in HS-responsive $\mathrm{H}_{2} \mathrm{O}_{2}$ production), respectively, in a cngc6 background. Real-time reverse transcriptionpolymerase chain reactions and Western blotting suggested that CNGC6 enhanced the gene transcription of $\mathrm{HS}$ factors (HSFs) and the accumulation of HS proteins (HSPs) via $\mathrm{H}_{2} \mathrm{O}_{2}$. These upon results indicate that $\mathrm{H}_{2} \mathrm{O}_{2}$ acts downstream of CNGC6 in the HS signaling pathway, increasing our understanding of the initiation of plants responses to high temperatures.

Keywords: heat shock, heat shock (stress) proteins, hydrogen peroxide, Arabidopsis, calcium ion

\section{INTRODUCTION}

Global warming is a serious environmental threat, and is an important limiting factor for normal plant growth and development. As fixed organisms, plants cannot escape from high temperature, but they have evolved methods and morphological variations to escape from its negative effects. As a countermeasure to heat shock (HS), plants can synthesize a series of 
HS proteins (HSPs) in the responses of cell to HS conditions. They act as molecular chaperones, ubiquitin, and certain proteases to counteract protein denaturation, aggregation, and degradation, which protect the plant cells from heat-damage (Lawas et al., 2018). Thus, the synthesis of HSP is especially important for plant survival under HS conditions. In eukaryotes, HSP induction is dependent on HS factors (HSFs), which act as transcription factors to be bound in HS elements in the promoter regions of HSP genes (Akerfelt et al., 2010).

Several reactive oxygen species (ROS) are constantly generated as by-products of aerobic metabolism at multiple locations in plant cells, including the photosynthetic electron transport chain in chloroplasts, NADPH oxidase in the plasma membrane (PM), and peroxidase in the cell wall (Gechev and Hille, 2005). They are always greatly toxic and swiftly detoxified by different cellular enzymatic and nonenzymatic mechanisms. In other situation, plants purposefully release ROS as signal molecules to initial various biological processes including stress defense, programmed cell death, and stomatal behavior. Hydrogen peroxide $\left(\mathrm{H}_{2} \mathrm{O}_{2}\right)$, as the major and most stable type of ROS, plays a key role in resistance reactions in plant cells, and it primarily originates from PM NADPH oxidase. In Arabidopsis, NADPH oxidase is encoded by 10 genes, from AtRbohA to AtRbohJ, which have distinct and shared biological features (Macpherson et al., 2008).

For example, $\mathrm{H}_{2} \mathrm{O}_{2}$ generated from AtRbohD and AtRbohF acts as a signaling molecule in ABA-induced stomatal closure and is crucial for jasmonic acid-induced expression of genes controlled by the MYC2 transcription factor (Maruta et al., 2011; Iwai et al., 2019), but regulates lateral root development negatively by altering the localization of superoxide in primary roots of Arabidopsis ( $\mathrm{Li}$ et al., 2015). Under Cd stress, the differential regulation of $\mathrm{H}_{2} \mathrm{O}_{2}$ metabolism, redox homeostasis, and nutrient balance by AtRbohC, AtRbohD, and AtRbohF is of potential interest for biotechnology applications for the phytoremediation of polluted soils (Gupta et al., 2017). AtRbohF is considered a key modulator of defense-associated metabolism and a crucial factor in the interplay between intracellular oxidative stress and pathogenesis responses in Arabidopsis (Chaouch et al., 2012). In addition, the level of $\mathrm{H}_{2} \mathrm{O}_{2}$ has been reported to increase following exposure to high temperatures, resulting in elevated HSF activation and HSP accumulation (Banti et al., 2010), whereas peroxide scavengers and inhibitors of $\mathrm{H}_{2} \mathrm{O}_{2}$ generation inhibited HSP expression in HS-exposed plants (Königshofer et al., 2008), implicating the involvement of $\mathrm{H}_{2} \mathrm{O}_{2}$ in the $\mathrm{HS}$ signaling pathway. Mutations in $A t R b o h B$ and $A t R b o h D$, two isoforms of NADPH oxidase which contribute to $\mathrm{H}_{2} \mathrm{O}_{2}$ production, were reported to show weaker defects under HS (Larkindale et al., 2005). Our work further indicated that AtRbohB and AtRbohD-dependent $\mathrm{H}_{2} \mathrm{O}_{2}$ production acts upstream of nitric oxide $(\mathrm{NO})$ in the $\mathrm{HS}$ signaling pathway, involving variations in HSF DNA-binding activity and HSP expression (Wang et al., 2014).

Calcium ions $\left(\mathrm{Ca}^{2+}\right)$ mobilization is a core issue in various plant signaling pathways. Cyclic nucleotide-gated ion channels (CNGCs) are nonselective cation channels and the main entrances for $\mathrm{Ca}^{2+}$ influxes into cells (Jha et al., 2016). In Arabidopsis genome, there are 20 expressed CNGC genes, having both different and shared biological activities (Talke et al., 2003). For example, cyclic nucleotide-gated ion channel 6 (CNGC6), CNGC9, and CNGC14 fulfill part of redundant functions to generate and maintain tip focused $\mathrm{Ca}^{2+}$ oscillations, which are essential for proper root hair growth and polarity (Brost et al., 2019). CNGC2 and CNGC4-mediated $\mathrm{Ca}^{2+}$ entry is suggested to provide a vital link between the pattern-recognition receptor complex and $\mathrm{Ca}^{2+}$-dependent immunity programs in PAMPtriggered immunity signal pathways in plants (Tian et al., 2019). The pollen-tube-specific CNGC7, CNGC8, and CNGC18 together with calmodulin $(\mathrm{CaM})$ constitute a molecular switch that control the open or close of the calcium channel depending on cellular $\mathrm{Ca}^{2+}$ levels (Pan et al., 2019). CNGC9 is reported to mediate the elevation of cytosolic $\mathrm{Ca}^{2+}\left(\left[\mathrm{Ca}^{2+}\right]_{\mathrm{cyt}}\right)$ to resist disease in rice (Wang et al., 2019). CNGCs are also believed to mediate $\mathrm{Ca}^{2+}$ signals in the HS pathway. We reported that CNGC6, a heat-responsive PM $\mathrm{Ca}^{2+}$-permeable channel, is associated with the expression of HSP genes and the acquisition of thermotolerance in Arabidopsis (Gao et al., 2012). CNGC6 via $\mathrm{Ca}^{2+}$ signaling initiates plant resistant reactions to heat stress, but its precise regulatory mechanisms remain obscure. Further investigations into HS signaling will enrich our understanding of the initial heat stress signaling processes.

Calcium ions and $\mathrm{H}_{2} \mathrm{O}_{2}$ are well known as two universal intracellular secondary messengers. Studies of plants have shown a close relationship between their individual pathways; however, there is controversy regarding which one is upstream of the other. Lots of studies implicate a specific role of $\mathrm{H}_{2} \mathrm{O}_{2}$ in regulating $\mathrm{Ca}^{2+}$ signaling. For example, $\mathrm{H}_{2} \mathrm{O}_{2}$ production regulates the elevation of $\left[\mathrm{Ca}^{2+}\right]_{\text {cyt }}$ in ABA signaling pathways in Arabidopsis guard cells (Jiang et al., 2013; Islam et al., 2019). On the contrary, some studies have pointed to the role of $\mathrm{Ca}^{2+}$ in influencing $\mathrm{H}_{2} \mathrm{O}_{2}$ signaling. For example, extracellular $\mathrm{Ca}^{2+}$ through $\mathrm{H}_{2} \mathrm{O}_{2}$ alleviates $\mathrm{NaCl}$-induced stomatal openings in Vicia guard cells (Zhao et al., 2011). Also, crosstalk between $\mathrm{Ca}^{2+}$ signaling and $\mathrm{H}_{2} \mathrm{O}_{2}$ is required for some signaling networks, for example, their co-operation in the process of heavy metal stress resistance (Nazir et al., 2020). The relationship between $\mathrm{Ca}^{2+}$ and $\mathrm{H}_{2} \mathrm{O}_{2}$ is not yet fully understood in plants exposed to HS conditions.

In this investigation, we used the model plant Arabidopsis to explore the relationship between $\mathrm{H}_{2} \mathrm{O}_{2}$ and the $\mathrm{Ca}^{2+}$-permeable channel CNGC6 under heat stress conditions. Our results demonstrate the involvement of $\mathrm{H}_{2} \mathrm{O}_{2}$ in CNGC6 signaling as a downstream factor in the HS signaling pathway, by stimulating Hsf transcription and HSP accumulation.

\section{MATERIALS AND METHODS}

\section{Plant Materials and Growth Conditions}

The wild-type (WT) and mutant Arabidopsis were Col-0 ecotype. atrbohB and atrbohD mutant seeds were obtained from Dr. Miguel Angel Torress (University of North Carolina). The triple mutant $c n g c 6 / r b o h B / D$ was obtained by crossing, while the transgenic lines cngc6/35S::RbohB-1, cngc6/35S::RbohB-2, 
cngc6/35S::RbohD-1, and cngc6/35S::RbohD-2 were obtained using the floral dip method.

The Arabidopsis seeds were surface sterilized in 2\% (v/v) sodium hypochlorite for $1 \mathrm{~min}$ and then washed thoroughly with water. The sterilized seeds were placed on Murashige and Skoog (MS) medium containing 3\% sucrose and $0.7 \%$ agar and kept at $4{ }^{\circ} \mathrm{C}$ in the dark for 3 days. The plants were then transferred to a growth chamber set at $22^{\circ} \mathrm{C}$ and $120 \mu \mathrm{mol}$ $\mathrm{m}^{-2} \mathrm{~s}^{-1}$ on a 16 -h daily light period.

For chemical treatment, $2 \mathrm{ml}$ of $\mathrm{H}_{2} \mathrm{O}_{2}$ at various concentrations $(0,25,50,100$, and $200 \mu \mathrm{M}$; Sigma-Aldrich, St. Louis, MO) were sprinkled onto the leaf surfaces of 8-day-old seedlings after filter sterilization. Sterilized water was used as a substitute for the control of seedlings. After $8 \mathrm{~h}$ of pre-treatment, the seedlings were subjected to HS conditions (Wang et al., 2014). In addition, $5 \mathrm{mM} \mathrm{CaCl}$ or $2 \mathrm{mM}$ EGTA (these reagents were prepared with sterilized water) was used to pre-treat the WT, $c n g c 6$, and COM12 seeds for $30 \mathrm{~min}$ before their being placed on MS medium in the fluorescence experiment, with sterilized water as the control.

\section{Thermotolerance Testing}

About 8-day-old seedlings, grown at $22^{\circ} \mathrm{C}$, were incubated in sterilized $5 \mathrm{mM} \mathrm{CaCl}_{2}$ at $37^{\circ} \mathrm{C}$ for $30 \mathrm{~min}$, returned to $22^{\circ} \mathrm{C}$ for $2 \mathrm{~h}$, then challenged at $45^{\circ} \mathrm{C}$ for $100 \mathrm{~min}$, and then returned to $22^{\circ} \mathrm{C}$ for 5 days of recovery (Lewis et al., 2016). The seedlings that were still green and continuing to produce new leaves were registered as survivors. For Western blotting, 10-day-old seedlings were kept at $37^{\circ} \mathrm{C}$ for $2 \mathrm{~h}$ and collected for the analyses of HSP accumulation. All the experiments were repeated at least three times, and there were three independent biological replicates in each repeat (Peng et al., 2019).

\section{Fluorescence Microscopy}

Hydrogen peroxide was visualized using the specific fluorescent probe 5-(and-6)-chloromethyl-29,79-dichlorodihydrofluorescein diacetate $\left(\mathrm{CM}-\mathrm{H}_{2} \mathrm{DCFDA}\right.$; Invitrogen) as described previously (Wang et al., 2010) with some modifications. Wild-type and mutant seedlings were incubated in $1 \mathrm{ml}$ of liquid MS medium (pH 5.8) with $10 \mu \mathrm{M} \mathrm{CM}-\mathrm{H}_{2} \mathrm{DCFDA}$ for $20 \mathrm{~min}$. Thereafter, the roots were washed three times for $15 \mathrm{~min}$ each in liquid MS medium prior to visualization with a fluorescence microscope (Eclipse TE 200, Nikon, Tokyo, Japan). The signal intensities were calculated using MetaMorph (Molecular Devices, Sunnyvale, CA).

\section{Vector Construction and the Generation of Transgenic Plants}

To generate the $35 S: 6 \times M y c-R b o h B$ construct, the full-length $R b o h B$ coding sequence was amplified using the primers 5'-CGGGATC-CATGCGGGAGGAAGAAATG-3' and 5'-TCCA CAAGGAAAATTTCTAGCTGCAGTT-3'. To generate the 35S:6 $\times M y c-R b o h D$ construct, the full-length RbohD coding sequence was amplified with the primers 5'-CGGGATCCATGA AAATGAGACGAGGCAA-3' and 5'-CCACAAAGAGAACTTCT AGCTGCAGTT-3'. The products were cloned in the pCAMBIA1307-6 $\times M y c$ vectors using the BamHI and PstI sites.
The transformation of the constructs into Arabidopsis (cngc6) was performed according to the floral dip method (Clough and Bent, 1998) with Agrobacterium tumefaciens (strain GV3101). Transformants were screened on plates containing $15 \mathrm{mg} \mathrm{l}^{-1}$ of Basta. Homozygous T3 transgenic lines were selected for further analysis.

\section{RT-qPCR Analysis}

Total RNA (500 ng) was isolated from 10-day-old seedlings at $37^{\circ} \mathrm{C}$ for $1 \mathrm{~h}$ with a PrimeScript RT Reagent Kit (Takara Bio Inc., Otsu, Japan) for first-stand cDNA synthesis, as per the manufacturer's instructions. The program was as follows: initial polymerase activation for $10 \mathrm{~s}$ at $95^{\circ} \mathrm{C}$ followed by 40 cycles of $95^{\circ} \mathrm{C}$ for $5 \mathrm{~s}$ and $60^{\circ} \mathrm{C}$ for $31 \mathrm{~s}$. The reactions were performed using an ABI Prism 7,000 sequence detection system (Applied Biosystems, Foster City, CA) with SYBR Premix Ex Taq (Takara Bio Inc.). Primer pairs were designed using Primer Express (Applied Biosystems). Detailed primer sequences are shown in Supplementary Table 1.

\section{Western Blot Analysis}

About 10 -day-old seedlings were kept at $37^{\circ} \mathrm{C}$ for $2 \mathrm{~h}$ and then ground in liquid nitrogen. Total protein was extracted with an extraction buffer (10 mM HEPES, pH 7.9, containing $0.4 \mathrm{M} \mathrm{NaCl}, 0.5 \mathrm{mM}$ dithiothreitol, $0.1 \mathrm{mM}$ EDTA, 5\% glycerol, and $0.5 \mathrm{mM}$ phenylmethanesulfonyl fluoride), and the extracts were purified by centrifugation at $14,000 \times g$ for $20 \mathrm{~min}$ at $4^{\circ} \mathrm{C}$. The supernatants were transferred to fresh tubes, and the protein content was measured according to the description of Bradford (1976). Total proteins $(50 \mu \mathrm{g})$ were analyzed by Western blotting, as described previously (Wang et al., 2014).

\section{Preparation of Protoplasts and Electrophysiology Analysis}

Protoplasts were isolated as described previously (Demidchik and Tester, 2002) from $1 \mathrm{~cm}$ long of root tips of Arabidopsis seedlings cultivated vertically at $22^{\circ} \mathrm{C}$ for 8 days. Whole-cell voltage patchclamping was carried out as described previously (Gao et al., 2012; Peng et al., 2019; Niu et al., 2020) with minor modification. Patch-clamp pipettes were pulled on a vertical electrode puller. The electrode was filled with pipette solution $[0.5 \mathrm{mM} \mathrm{CaCl}$, $2 \mathrm{mM}$ Mg-ATP, $0.5 \mathrm{mM}$ Tris-ATP, $4 \mathrm{mM} \mathrm{Ca}(\mathrm{OH})_{2}, 10 \mathrm{mM}$ EGTA and $15 \mathrm{mM}$ HEPES/Tris, pH 7.2, adjusted to an osmolality of $300 \mathrm{mOsm} / \mathrm{kg}$ with sorbitol; free $\mathrm{Ca}^{2+}$ concentration $100 \mathrm{nM}$ ]. The basal external solution comprised $10 \mathrm{mM} \mathrm{CaCl}_{2}$ and $5 \mathrm{~mm}$ MES/Tris, pH 5.8, adjusted to an osmolality of $300 \mathrm{mOsm} / \mathrm{Kg}$ with sorbitol. The resistance of the electrode in the bath solution was approximately $20 \mathrm{M} \Omega$. Seal resistances were up to $2 \mathrm{G} \Omega$. After holding the whole-cell high seal resistances for $20 \mathrm{~min}$, currents were recorded and data were sampled at $1 \mathrm{kHz}$ and filtered at $200 \mathrm{~Hz}$. Membrane potentials were corrected for liquid junction potentials and series resistance. An Axon 200B amplifier controlled by pCLAMP 9.0 software (Molecular Devices) was used to record the current signal. Basal currents were recorded at room temperature $\left(20-22^{\circ} \mathrm{C}\right)$. HS treatment $\left(37 \pm 1^{\circ} \mathrm{C}\right)$ was performed using continuous bath perfusion. 


\section{RESULTS}

\section{Effects of HS on $\mathrm{H}_{2} \mathrm{O}_{2}$ Production in the Wild-Type, cngc6, and a Complemented Line COM12 Seedlings}

In this work, we presented evidence for the involvement of $\mathrm{H}_{2} \mathrm{O}_{2}$ in $\mathrm{Ca}^{2+}$ signaling in plant thermotolerance. CNGC6, activated by $\mathrm{HS}$ and mediated $\mathrm{Ca}^{2+}$ influxes, functioned as a signal in the induction of $\mathrm{H}_{2} \mathrm{O}_{2}$ generation to stimulate the transcription of Hsfs and HSPs accumulation. Thus, CNGC6 was found to promote heat tolerance in Arabidopsis seedlings.

Hydrogen peroxide is a plant signaling molecule that plays a vital role in many environmental stress responses. Lots of studies suggest a key role for CNGCs in controlling $\mathrm{H}_{2} \mathrm{O}_{2}$ production (Walker and Berkowitz, 2013; Cui et al., 2020). To elucidate the relationship between $\mathrm{H}_{2} \mathrm{O}_{2}$ and CNGC6 in thermotolerance, we first determined the transcription levels of $A t R b o h B$ and $A t R b o h D$ at the seedling stage using the wild-type plants, a T-DNA insertion mutant (cngc6; SALK_042207), and a complementation line (COM12; cngc6 + CNGC6; Gao et al., 2012). The result showed that no clear difference existed between the expression levels in these seedlings under normal conditions; however, both of their expression levels were stimulated by high temperatures and varied depending on the expression level of CNGC6 (Supplementary Figure 1), implying that it had a role in the generation of $\mathrm{H}_{2} \mathrm{O}_{2}$. Thus, we examined endogenous $\mathrm{H}_{2} \mathrm{O}_{2}$ accumulations in these seedlings using the special fluorescent probe $\mathrm{CM}-\mathrm{H}_{2} \mathrm{DCFDA}$. This probe can be transported into cells, where its acetate groups are passively cleaved by intracellular esterases, producing the fluorescent compound dichlorodihydrofluorescein (DCF; Chozinski et al., 2016).

Fluorescence analysis indicated that under normal conditions $\left(22^{\circ} \mathrm{C}\right)$, no clear difference in the abundance of $\mathrm{H}_{2} \mathrm{O}_{2}$ was observed among the seedlings. After $\mathrm{HS}$ treatment at $45^{\circ} \mathrm{C}$ for 30 min (Wang et al., 2014), the $\mathrm{H}_{2} \mathrm{O}_{2}$ level increased by $208 \%$ in the wild-type seedlings, higher than the increase observed in cngc6 (108\%); however, it was nearly rescued in COM12 seedlings (187\%; Figures 1A,B). We also found that not all the production of $\mathrm{H}_{2} \mathrm{O}_{2}$ responsive to $\mathrm{HS}$ was inhibited in $n c g c 6$ mutant. Thus, these results suggest that the production of $\mathrm{H}_{2} \mathrm{O}_{2}$ observed after HS treatment was partially due to the activation of CNGC6.

\section{Effect of $\mathrm{Ca}^{2+}$ on the $\mathrm{H}_{2} \mathrm{O}_{2}$ Accumulation in the Wild-Type Seedlings}

Cyclic nucleotide-gated ion channel 6 is a heat-responsive $\mathrm{Ca}^{2+}$ permeable channel in the PM of plant cells (Gao et al., 2012). $\mathrm{Ca}^{2+}$ is one of the most multifunctional ions existed in eukaryotes, and it has been confirmed to coordinate with $\mathrm{H}_{2} \mathrm{O}_{2}$ in many physiological processes (Ferreira et al., 2003). Thus, it is reasonable to consider that CNGC6 elevates the $\mathrm{H}_{2} \mathrm{O}_{2}$ level through $\mathrm{Ca}^{2+}$ to induce thermotolerance.

To test this hypothesis, the $\mathrm{H}_{2} \mathrm{O}_{2}$ levels were examined in the wild-type, cngc6, and COM12 seedlings pre-treated with $5 \mathrm{mM} \mathrm{CaCl}_{2}$ or $2 \mathrm{mM} \mathrm{EGTA} \mathrm{(a} \mathrm{Ca}{ }^{2+}$ chelator) before germination as described previously (Liu et al., 2005; Peng et al., 2019). Fluorescence analysis showed that under normal growth conditions, the $\mathrm{H}_{2} \mathrm{O}_{2}$ levels in wild-type, cngc6, and COM12 seedlings were rather stable. However, under HS conditions, $5 \mathrm{mM} \mathrm{Ca}^{2+}$ treatment elevated the $\mathrm{H}_{2} \mathrm{O}_{2}$ level to 411, 303, and $389 \%$ of their individual controls in the wild-type, cngc6, and COM12 seedlings, respectively. Whereas $2 \mathrm{mM}$ EGTA reduced the increase in $\mathrm{H}_{2} \mathrm{O}_{2}$ to 245 and $213 \%$ of the wildtype and COM12 controls, respectively, but there was no clear effect on the cngc6 mutant (Figures 1C-H).

\section{Effects of $\mathrm{H}_{2} \mathrm{O}_{2}$ on the Thermotolerance of cngc6 Seedlings}

Subsequently, a solution containing a series of concentrations of $\mathrm{H}_{2} \mathrm{O}_{2}$ was used to pre-treat the wild-type and $c n g c 6$ seedlings. Under HS conditions, the internal $\mathrm{H}_{2} \mathrm{O}_{2}$ level was higher in the wild-type seedlings than in the cngc6 seedlings. Exogenous application of $\mathrm{H}_{2} \mathrm{O}_{2}$ stimulated the internal $\mathrm{H}_{2} \mathrm{O}_{2}$ level in these seedlings depending on the $\mathrm{H}_{2} \mathrm{O}_{2}$ concentration, reaching a maximum value at $100 \mu \mathrm{M}$ and decreasing slightly at $200 \mu \mathrm{M}$ (Figures 2A,B). The survival ratios of the wild-type and $c n g c 6$ seedlings changed in the same manner as their internal $\mathrm{H}_{2} \mathrm{O}_{2}$ levels, reaching the maximum at $100 \mu \mathrm{M}$ (Figures 2C,D).

Taken together, these results (Figures 1, 2) showed that heat-responsive $\mathrm{Ca}^{2+}$ channel CNGC6 regulated $\mathrm{H}_{2} \mathrm{O}_{2}$ production; however, an increased internal $\mathrm{H}_{2} \mathrm{O}_{2}$ level rescued the impaired thermotolerance of the CNGC6-deficient mutant, indicating $\mathrm{H}_{2} \mathrm{O}_{2}$ involvement in CNGC6 signaling as a downstream factor.

\section{AtRbohB and AtRbohD Overexpression in a cngc6 Background Increases Thermotolerance}

We even reported that $\mathrm{H}_{2} \mathrm{O}_{2}$ acts as a signal in heat tolerance using the mutants rbohB and rbohD, which show poor thermotolerance due to a deficiency in $\mathrm{H}_{2} \mathrm{O}_{2}$ (Wang et al., 2014). To further investigate the effect of CNGC6 on $\mathrm{H}_{2} \mathrm{O}_{2}$ signaling under HS conditions, we obtained two AtRbohBoverexpressing transgenic lines, cngc6/35S::RbohB-1 and cngc6/35S::RbohB-2, and two AtRbohD-overexpressing transgenic lines, $c n g c 6 / 35 S:: R b o h D-1$ and $c n g c 6 / 35 S:: R b o h D-2$, and examined the influences of excess internal $\mathrm{H}_{2} \mathrm{O}_{2}$ on CNGC6-deficient mutants under HS conditions. The increased expression of AtRbohB and AtRbohD was confirmed according to real-time quantitative PCR (RT-qPCR; Figures 3A, 4A).

Dichlorodihydrofluorescein fluorescence analysis indicated that $A t R b o h B$ and $A t R b o h D$ overexpression enhanced the internal $\mathrm{H}_{2} \mathrm{O}_{2}$ levels in these transgenic plants under normal and HS conditions (Figures 3, 4). Under normal conditions, no clear phenotypic difference was observed between cngc6 mutant and these transgenic lines. However, under high temperature conditions, $A t R b o h B$ or $A t R b o h D$ overexpression greatly improved the survival ratio of the transgenic lines in comparison with their background cngc6 according to their individual transcriptional levels (Figures 3, 4).

These results showed that the overexpression of $A t R b o h B$ or AtRbohD restored heat tolerance in a CNGC6-deficient 

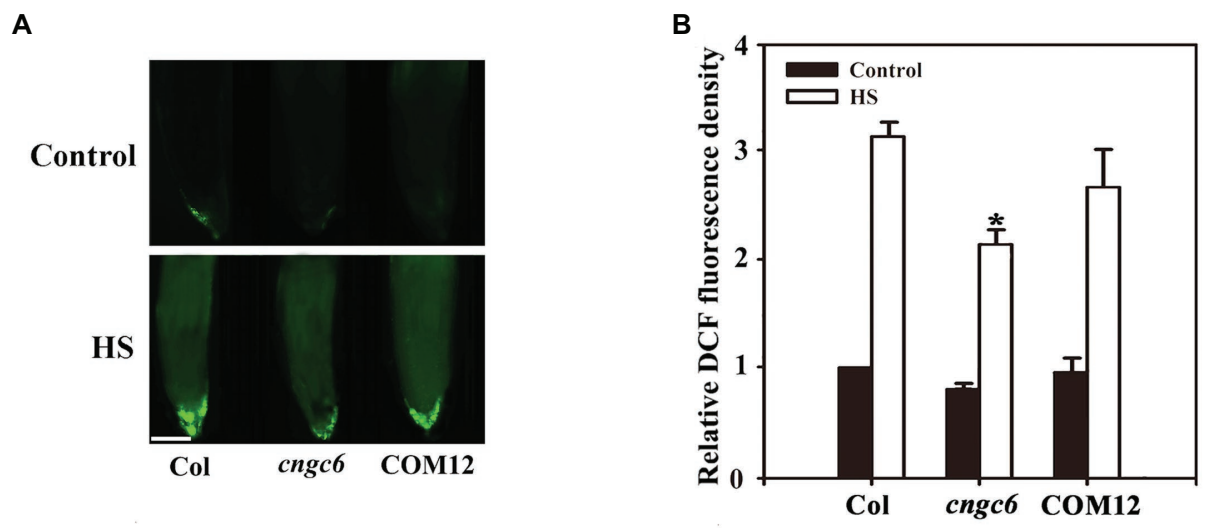

C

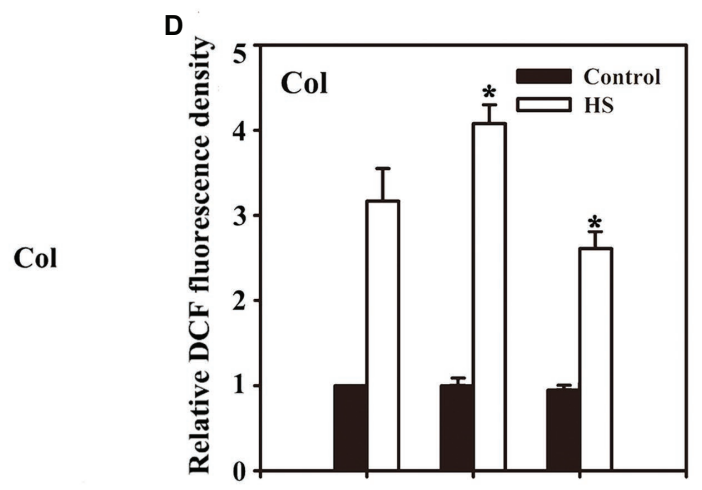

E
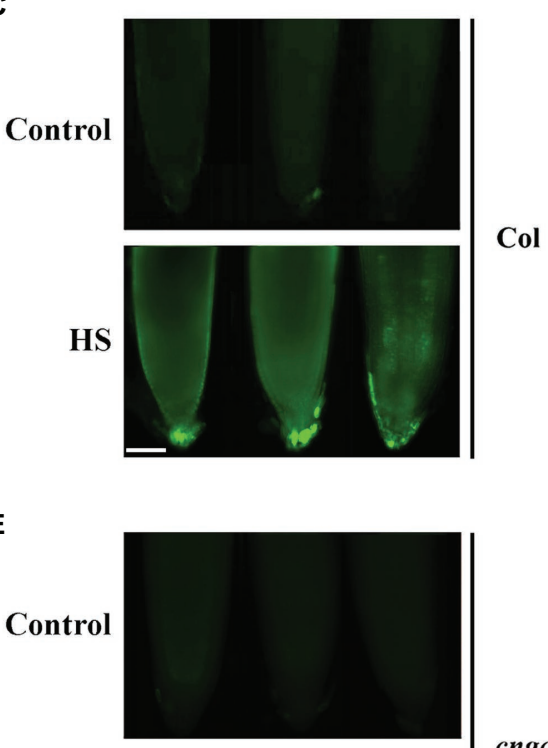

HS
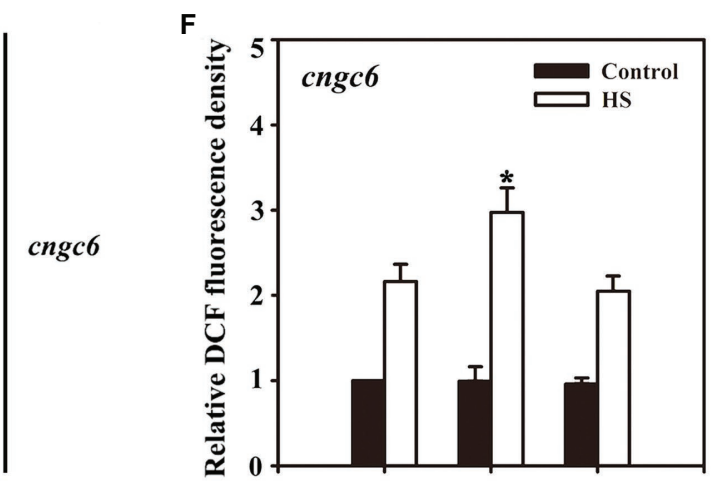

G
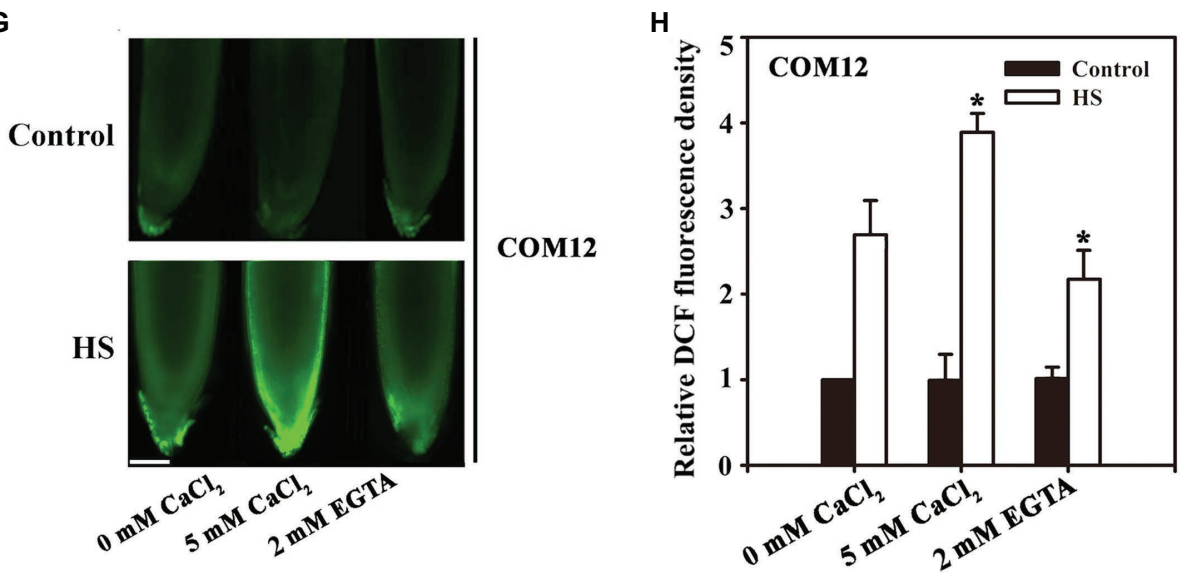
FIGURE 1 | Effects of calcium ions $\left(\mathrm{Ca}^{2+}\right)$ on hydrogen peroxide $\left(\mathrm{H}_{2} \mathrm{O}_{2}\right)$ accumulation in Arabidopsis seedlings. (A) About 8-day-old wild-type (WT), cngc6, and COM12 seedlings grown at $22^{\circ} \mathrm{C}$ were exposed to $45^{\circ} \mathrm{C}$ (heat shock, HS) or maintained at $22^{\circ} \mathrm{C}(\mathrm{Control})$ for 30 min. The $\mathrm{H}_{2} \mathrm{O}_{2}$ levels in the seedlings were then examined by fluorescence microscopy using roots dyed with 5-(and-6)-chloromethyl-29,79-dichlorodihydrofluorescein diacetate $\left(\mathrm{CM}-\mathrm{H}_{2} \mathrm{DCFDA}\right)$. Bar = 100 $\mu$ m. (B) Relative dichlorodihydrofluorescein (DCF) fluorescence densities in the roots. The data presented are the means \pm SE of measurements taken from five independent experiments with at least 10 roots for each treatment. ${ }^{*} p<0.05$ vs. Col (Student's $t$-test). (C,E,G) About 8 -day-old seedlings of wild-type (C), cngc6 (E), and COM2 (G) were exposed to $45^{\circ} \mathrm{C}(\mathrm{HS})$ or maintained at $22^{\circ} \mathrm{C}$ (Control) for 30 min. The $\mathrm{H}_{2} \mathrm{O}_{2}$ levels in the plants were then examined by fluorescence microscopy using roots stained with $\mathrm{CM}-\mathrm{H}_{2} \mathrm{DCFDA}$. Bar $=100 \mu \mathrm{m}$. (D,F,H) The relative DCF fluorescence densities in the roots of wild-type (D), cngc6 (F), and COM2 (H). The data presented are the means \pm SE of measurements taken from five independent experiments with at least 10 roots for each treatment. ${ }^{*} p<0.05$ vs. $0 \mathrm{mM} \mathrm{CaCl}_{2}$ (Student's $t$-test).
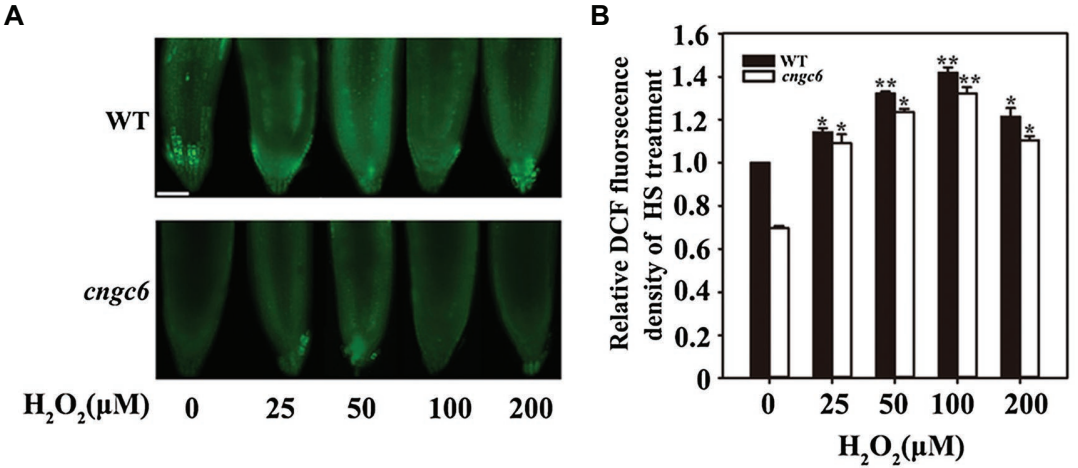

D

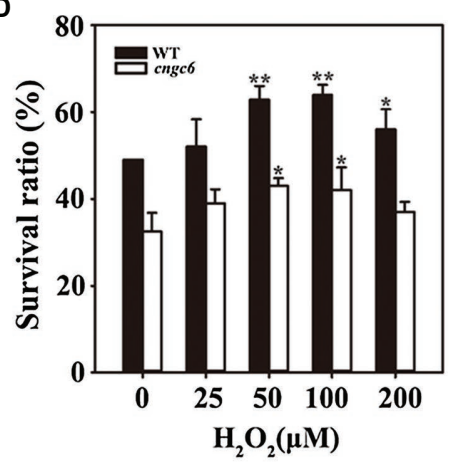

C

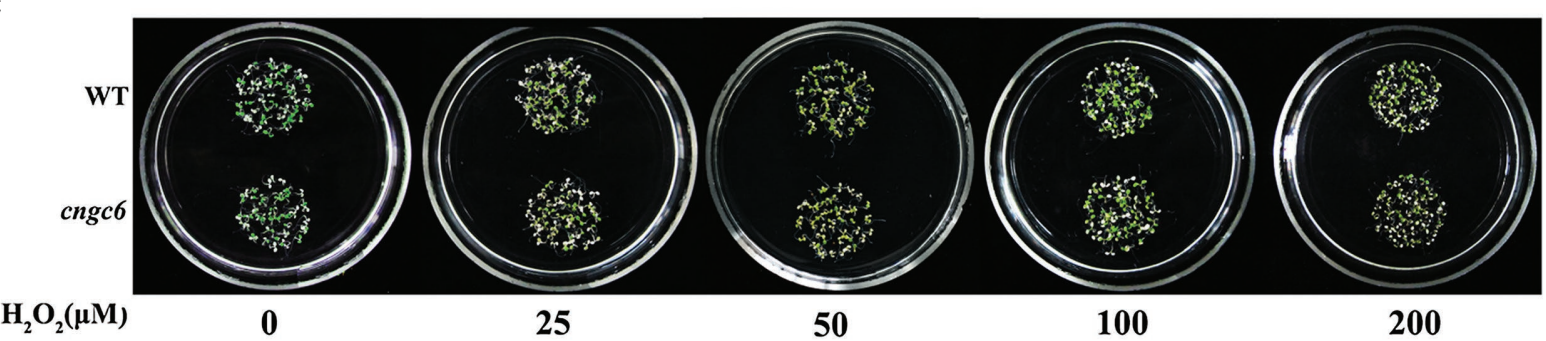

FIGURE 2 | Effects of $\mathrm{H}_{2} \mathrm{O}_{2}$ on the thermotolerance of WT and cngc6 seedlings. (A) About 8-day-old WT and cngc6 seedlings grown at $22^{\circ} \mathrm{C}$ were pre-treated with $2 \mathrm{ml}$ of $\mathrm{O}, 25,50,100$, or $200 \mathrm{mM} \mathrm{H}_{2} \mathrm{O}_{2}$ for $8 \mathrm{~h}$ and then exposed to $45^{\circ} \mathrm{C}(\mathrm{HS})$ for $30 \mathrm{~min}$. The $\mathrm{H}_{2} \mathrm{O}_{2}$ levels were then assessed by fluorescence microscopy in roots stained with CM-H2DCFDA. Bar $=100 \mathrm{~mm}$. (B) Relative DCF fluorescence densities in the roots. The data presented are means \pm SE of measurements taken from at least 10 roots for each treatment. ${ }^{\star} p<0.05$ and ${ }^{\star \star} p<0.01$ vs. $0 \mathrm{mM} \mathrm{H}_{2} \mathrm{O}_{2}$ (Student's $t$-test). (C) Seedlings were exposed to $45^{\circ} \mathrm{C}$ for 100 min, then returned to $22^{\circ} \mathrm{C}$ and photographed 5 days later. (D) Survival ratios of the seedlings after HS treatment. The data presented are means $\pm \mathrm{SE}$ of at least five independent experiments with 50 seedlings per experiment. ${ }^{*} p<0.05$ vs. $0 \mathrm{mM} \mathrm{H}_{2} \mathrm{O}_{2}$ (Student's $t$-test).

mutant, providing genetic proof for the relationship between CNGC6 and $\mathrm{H}_{2} \mathrm{O}_{2}$ in $\mathrm{HS}$ signaling.

\section{Effects of HS on the Thermotolerance of the cngc6/rbohB/D Triple-Mutant Seedlings}

To further examine the roles of CNGC6 and $\mathrm{H}_{2} \mathrm{O}_{2}$ in plant thermotolerance, we obtained the $c n g c 6 / r b o h B / D$ triple mutant by crossing, which was deficient in CNGC6, RbohB, and RbohD transcription according to RT-qPCR analysis (Figure 5A). Under normal and $\mathrm{HS}$ conditions, the $\mathrm{H}_{2} \mathrm{O}_{2}$ level in the $c n g c 6 / r b o h B / D$ seedlings was similar to that in the $r b o h B / D$ seedlings (Figures 5B,C), revealing that the deficiency of CNGC6 did not remarkably reduce $\mathrm{H}_{2} \mathrm{O}_{2}$ accumulation in the $r b o h B / D$ seedlings. Under normal conditions, $c n g c 6 / r b o h B / D$ seedlings showed similar phenotypes with other seedlings (Figure 5D, Control). Under HS conditions, the survival ratio of the $c n g c 6 / r b o h B / D$ seedlings was near to that of the $r b o h B / D$ seedlings (Figures 5D,E), showing that the deficiency of CNGC6 did not obviously aggravate the heat susceptibility of $\mathrm{rbohB} / \mathrm{D}$.

\section{Effects of $\mathrm{H}_{2} \mathrm{O}_{2}$ on the Activity of $\mathrm{Ca}^{2+}$-Permeable Channel}

The results provided evidence of the function of CNGC6 on the $\mathrm{H}_{2} \mathrm{O}_{2}$-mediated acquisition of heat tolerance. In Arabidopsis, a specific role for $\mathrm{H}_{2} \mathrm{O}_{2}$ in regulating $\mathrm{Ca}^{2+}$ mobilization has also been found (Islam et al., 2019).

To confirm whether $\mathrm{H}_{2} \mathrm{O}_{2}$ influences the action of heatresponsive $\mathrm{Ca}^{2+}$-permeable channels, we determined the effects of internal $\mathrm{H}_{2} \mathrm{O}_{2}$ on the function of CNCG6 in the PM of root protoplasts of Arabidopsis with the whole-cell patchclamp technique (Gao et al., 2012; Peng et al., 2019). Under normal conditions at $22^{\circ} \mathrm{C}$, the $\mathrm{Ca}^{2+}$ current in $\operatorname{cngc6}(-136$ $\mathrm{pA})$ was lower than in the wild-type $(-178 \mathrm{pA})$ at $-200 \mathrm{mV}$. Under $\mathrm{HS}$ at $37^{\circ} \mathrm{C}$, the inward $\mathrm{Ca}^{2+}$ current was swiftly 


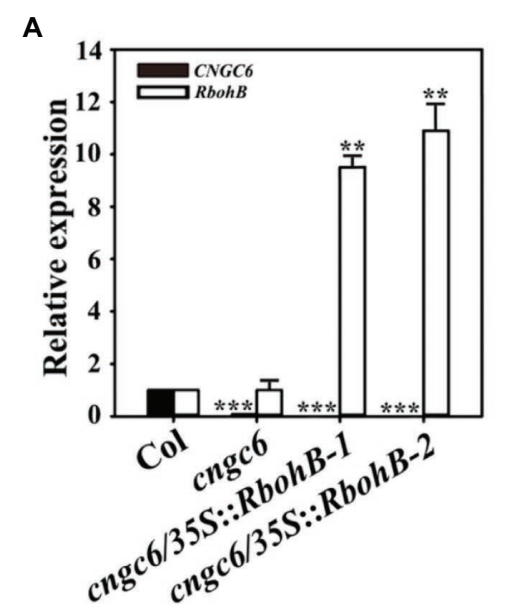

D

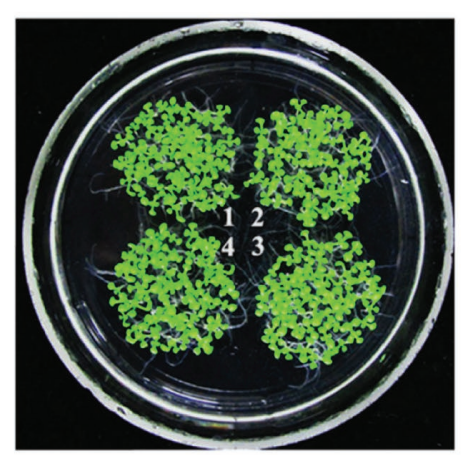

Control
B
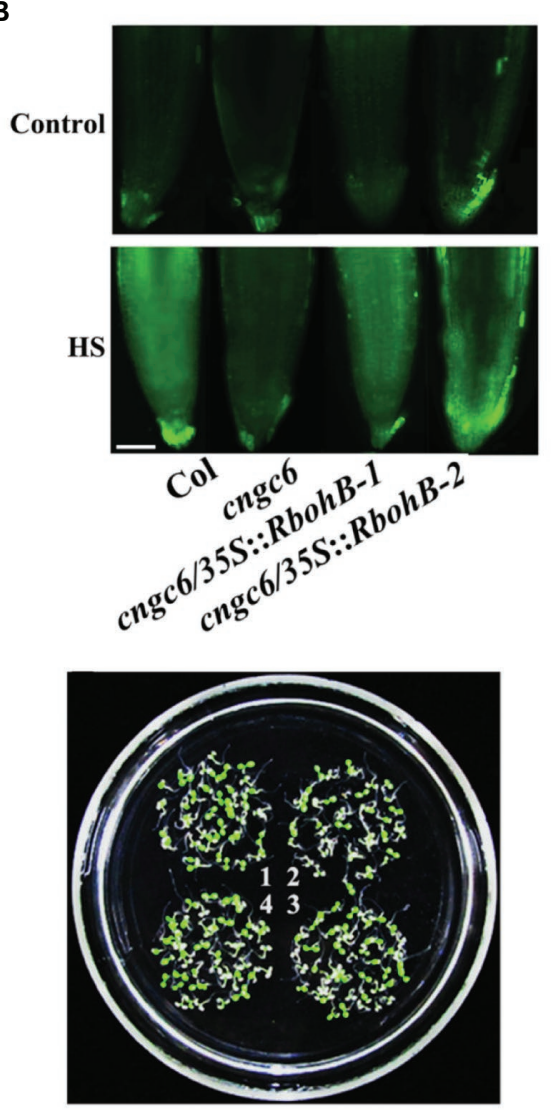

HS
C

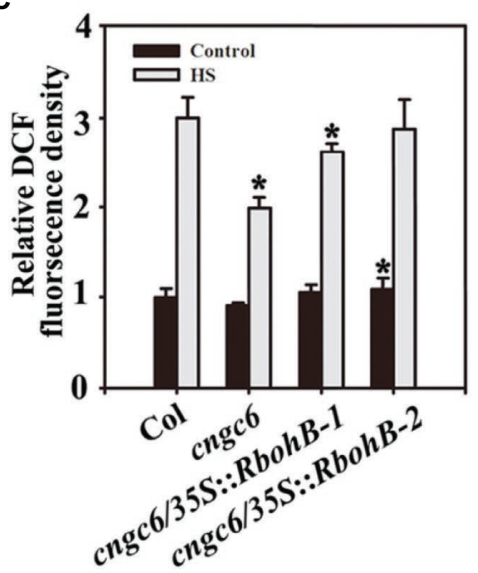

E

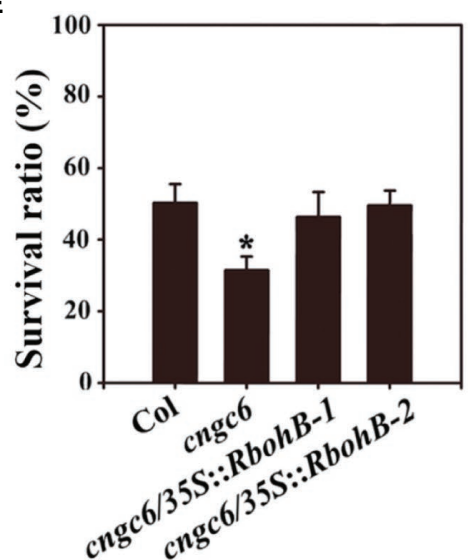

FIGURE 3 | Improved thermotolerance through AtRbohB overexpression in a cngc6 background. (A) Real-time quantitative PCR (RT-qPCR) analysis of AtCNGC6 and $A t R b o h B$ transcription in wild-type, cngc6, cngc6/35S::RbohB-1, and cngc6/35S::RbohB-2 plants. The experiments were repeated three times with similar results. Each data point represents the mean $\pm \operatorname{SD}(n=3)$. Asterisks indicate a significant difference relative to Col $\left(S t u d e n t ' s t\right.$-test: ${ }^{\star \star} p<0.01$ and $\left.{ }^{\star \star \star} p<0.001\right)$. (B) About 8-day-old wild-type, cngc6, cngc6/35S::RbohB-1, and cngc6/35S::RbohB-2 seedlings grown at $22^{\circ} \mathrm{C}$ were exposed to $45^{\circ} \mathrm{C}(\mathrm{HS})$ or maintained at $22^{\circ} \mathrm{C}$ (Control) for 30 min. The $\mathrm{H}_{2} \mathrm{O}_{2}$ levels in the plants were then examined by fluorescence microscopy using roots stained with $\mathrm{CM}-\mathrm{H}_{2} \mathrm{DCFDA}$. Bar = $100 \mathrm{\mu m}$. (C) The relative DCF fluorescence densities in the roots. The data presented are the means $\pm \mathrm{SE}$ of measurements taken from five independent experiments with at least 10 roots for each treatment. ${ }^{*} p<0.05$ vs. Col. (D) Seedlings grown at $22^{\circ} \mathrm{C}$ were exposed to $45^{\circ} \mathrm{C}(\mathrm{HS})$ or maintained at $22^{\circ} \mathrm{C}(\mathrm{Control})$ for 100 min, then returned to $22^{\circ} \mathrm{C}$ and photographed 5 days later. The clusters are as follows: 1, wild-type; 2, cngc6; 3, cngc6/35S::RbohB-1; and 4, cngc6/35S::RbohB-2. (E) Survival ratios of the seedlings after HS treatment. The data presented are the means \pm SE of at least five independent experiments with 50 seedlings per experiment. ${ }^{*} p<0.05$ vs. Col (Student's t-test).

elevated to $-375 \mathrm{pA}$ in the wild-type within $1 \mathrm{~min}$. However, only a slight increase (to $-171 \mathrm{pA}$ ) was observed in cngc6 (Figures 6A,B), in accordance with our previous reports (Gao et al., 2012; Peng et al., 2019; Niu et al., 2020). In the rbohB/D double mutant with low internal $\mathrm{H}_{2} \mathrm{O}_{2}$ levels, the $\mathrm{Ca}^{2+}$ currents exhibited similar changing trends to those in the wild-type under both of normal and HS conditions (Figure 6C). However, in the $c n g c 6 / r b o h B / D$ triple mutant, the $\mathrm{Ca}^{2+}$ currents showed no clear difference with those in cngc6 under normal and HS conditions (Figure 6D). In two transgenic lines with high endogenous $\mathrm{H}_{2} \mathrm{O}_{2}$ levels, cngc6/35S::RbohB-1 and cngc6/35S::RbohD-1, the Ca ${ }^{2+}$ currents were similar to those of $c n g c 6$ (non-transgenic background; Figures 6E,F), indicating that $\mathrm{H}_{2} \mathrm{O}_{2}$ had no obvious affection on the activity of $\mathrm{Ca}^{2+}$ channel.

\section{Effect of CNGC6 on the Transcription of Hsf and the Expression of AtHSP21 and AtHSP17.7 Through $\mathrm{H}_{2} \mathrm{O}_{2}$}

To investigate the underlying mechanisms of CNGC6- and $\mathrm{H}_{2} \mathrm{O}_{2-}$ induced plant thermotolerance, the mRNA level of $H s f$ in the wild-type, $c n g c 6, r b o h B / D$, and $c n g c 6 / r b o h B / D$ seedlings as well as in the two individual $R b o h B$ - and $R b o h D$-overexpressing transgenic lines (cngc6/35S::RbohB-1 and cngc6/35S::RbohD-1) was analyzed using RT-qPCR. Under normal conditions, there was no clear difference among the levels in these seedlings (Figure 7, Control). After the HS treatment, $H s f(H s f 2 A, H s f A 7 a$, and $H s f B 2 b)$ mRNA levels were dramatically elevated. However, in $c n g c 6, r b o h B / D$, and cngc6/rbohB/D seedlings, they were lower than in the wild-type seedlings (and lowest for $c n g c 6 / r b o h B / D$ ) but they were significantly 
A

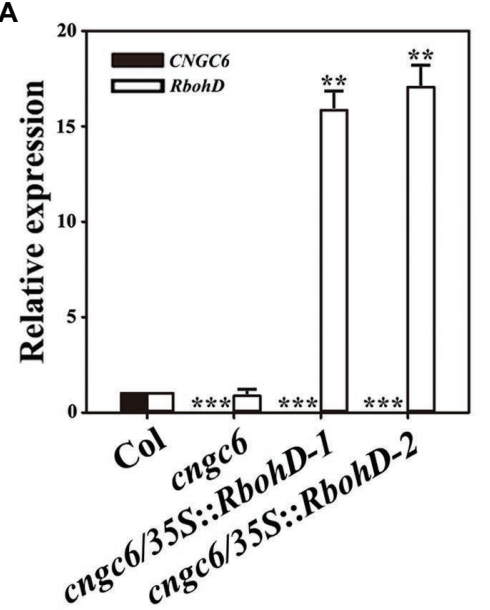

D

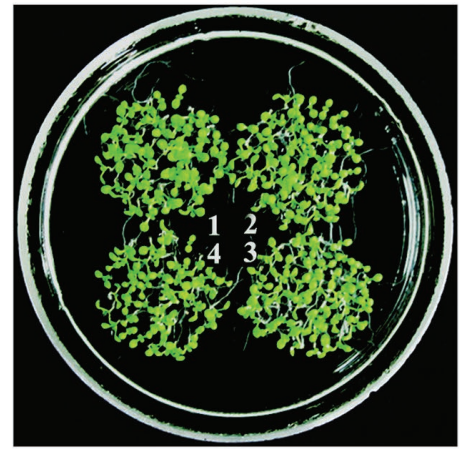

Control
B
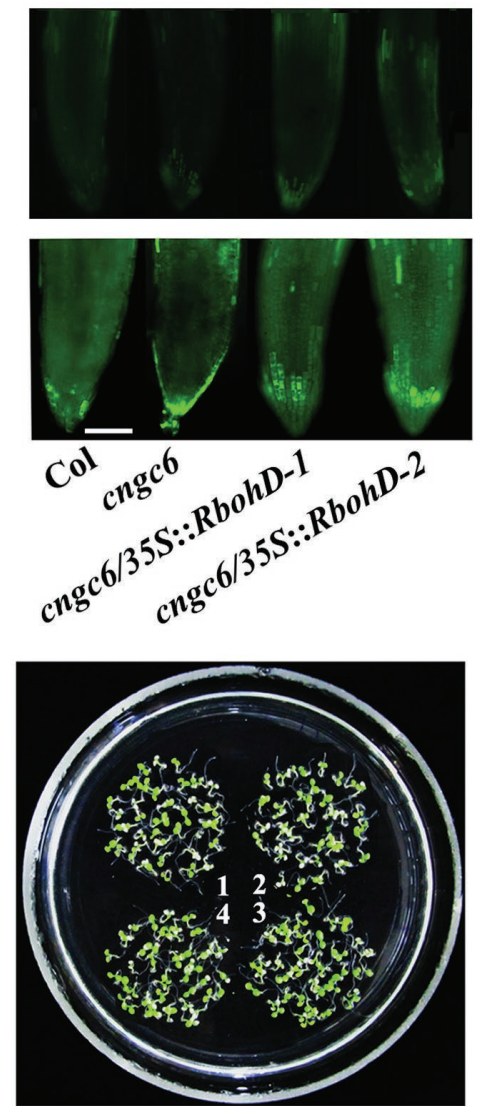

HS
C

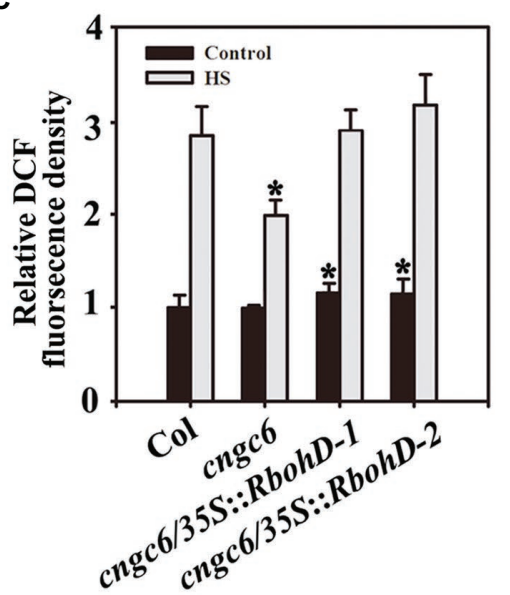

E

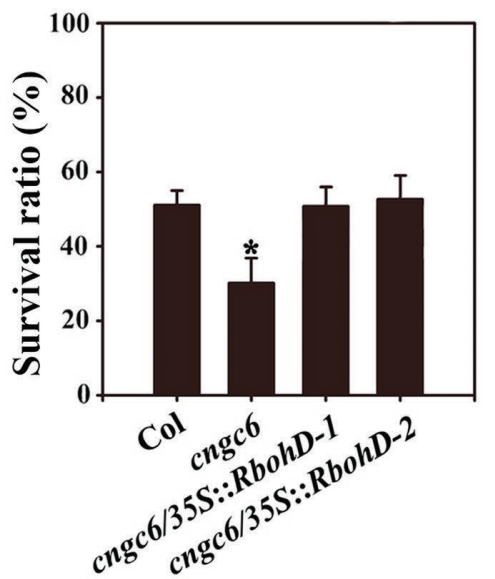

FIGURE 4 | Improved thermotolerance through AtRbohD overexpression in a cngc6 background. (A) RT-qPCR analysis of AtCNGC6 and AtRbohD transcription in wild-type, cngc6, cngc6/35S::RbohD-1, and cngc6/35S::RbohD-2 plants. The experiments were repeated three times with similar results. Each data point represents the mean $\pm \operatorname{SD}(n=3)$. Asterisks indicate a significant difference relative to Col (Student's $t$-test: ${ }^{* *} p<0.01$ and $\left.{ }^{* \star *} p<0.001\right)$. (B) About 8 -day-old wildtype, cngc6, cngc6/35S::RbohD-1, and cngc6/35S::RbohD-2 seedlings grown at $22^{\circ} \mathrm{C}$ were exposed to $45^{\circ} \mathrm{C}(\mathrm{HS})$ or maintained at $22^{\circ} \mathrm{C}(\mathrm{Control})$ for 30 min. The $\mathrm{H}_{2} \mathrm{O}_{2}$ levels in the plants were then examined by fluorescence microscopy using roots stained with $\mathrm{CM}-\mathrm{H}_{2} \mathrm{DCFDA}$. Bar = $100 \mu \mathrm{m}$. (C) The relative DCF fluorescence densities in the roots. The data presented are the means \pm SE of measurements taken from five independent experiments with at least 10 roots for each treatment. ${ }^{*} p<0.05$ vs. Col. (D) Seedlings grown at $22^{\circ} \mathrm{C}$ were exposed to $45^{\circ} \mathrm{C}\left(\mathrm{HS}\right.$ ) or maintained at $22^{\circ} \mathrm{C}$ (Control) for 100 min, then returned to $22^{\circ} \mathrm{C}$ and photographed 5 days later. The clusters are as follows: 1 , wild-type; 2, cngc6; 3, cngc6/35S::RbohD-1; and 4, cngc6/35S::RbohD-2. (E) Survival ratios of the seedlings after HS treatment. The data presented are the means \pm SE of at least five independent experiments with 50 seedlings per experiment. ${ }^{*} p<0.05$ vs. Col (Student's $t$-test).

stimulated by $50 \mu \mathrm{M} \mathrm{H}_{2} \mathrm{O}_{2}$ and were activated in the two transgenic lines compared with their background cngc6 (Figure 7, HS).

Heat shock proteins, as molecular chaperones, are crucial for all organisms to survive under severe stress through the maintenance of proteostasis (Akerfelt et al., 2010). Thus, we subsequently determined the influences of CNGC6 and $\mathrm{H}_{2} \mathrm{O}_{2}$ on the expression of AtHSP17.7 and AtHSP21 in these plants using Western blotting analysis. Neither AtHSP17.7 nor AtHSP21 was observed at $22^{\circ} \mathrm{C}$; however, both of them accumulated at $37^{\circ} \mathrm{C}$ (Figure 8). The level of protein expression was lower in the mutants than in the wild-type (and lowest for $c n g c 6 / r b o h B / D$ ), and it was greatly elevated by $50 \mu \mathrm{M} \mathrm{H}_{2} \mathrm{O}_{2}$ in the $c n g c 6$ mutant. In addition, its accumulation was increased in the $c n g c 6 / 35 S:: R b o h B-1$ and $c n g c 6 / 35 S:: R b o h D-1$ plants in comparison with the cngc6 mutant (non-transformed background; Figure 8). In all these experiments, tubulin was adopted to ensure equal sample loading.

These results revealed that the application of $\mathrm{H}_{2} \mathrm{O}_{2}$ and the overexpression of AtRbohB or AtRbohD prompted HSP expression in a cngc6 mutant, providing further evidence that CNGC6 acts upstream of $\mathrm{H}_{2} \mathrm{O}_{2}$ in the $\mathrm{HS}$ pathway.

\section{DISCUSSION}

\section{The Relationships Among $\mathrm{Ca}^{2+}$, CNGC6, and $\mathrm{H}_{2} \mathrm{O}_{2}$ Accumulation in Plant} Thermotolerance in Arabidopsis Seedlings High external temperatures always result in elevated $\left[\mathrm{Ca}^{2+}\right]_{\mathrm{cyt}}$ and the accumulation of $\mathrm{H}_{2} \mathrm{O}_{2}$ in plant cells, as they play 


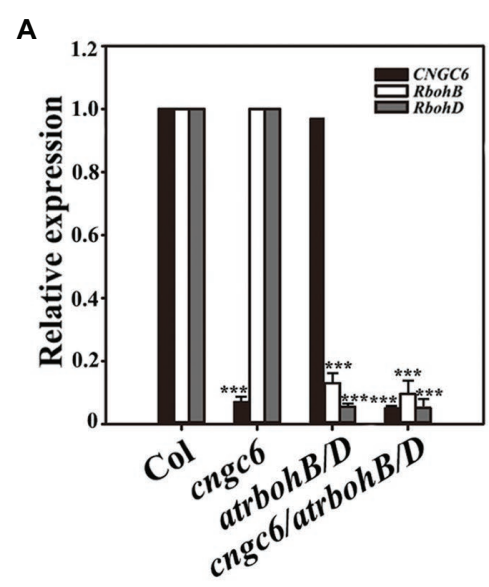

D

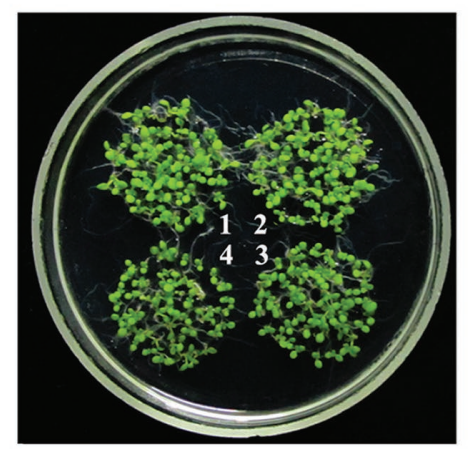

Control
B
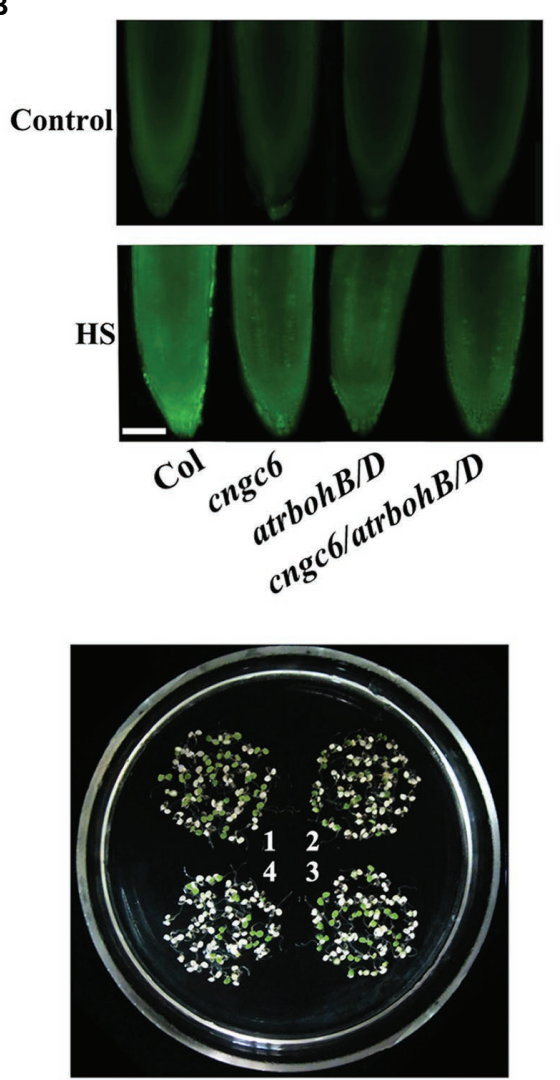

HS
C

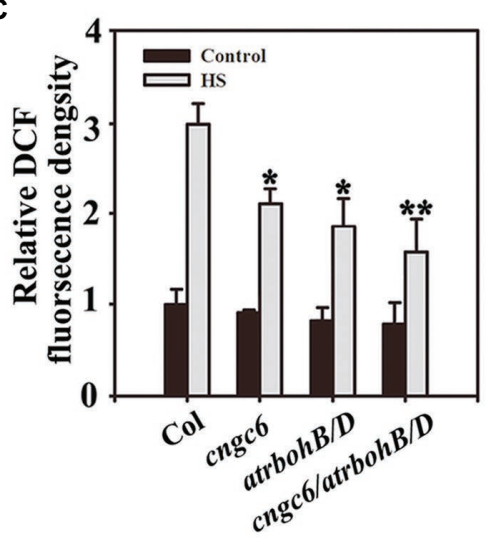

E

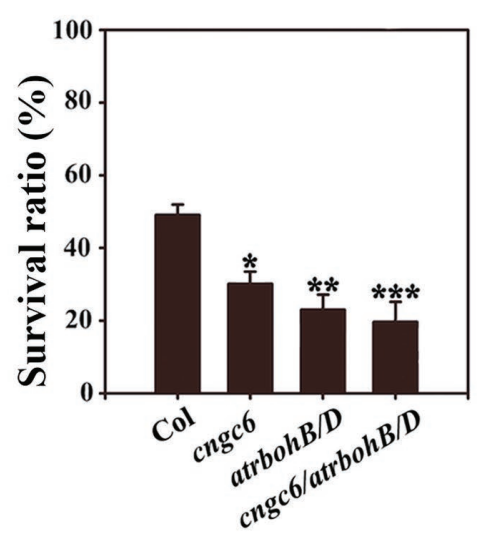

FIGURE 5 | Survival status of the cngc6/rbohB/D triple mutant. (A) RT-qPCR analysis of cyclic nucleotide-gated ion channel 6 (CNGC6), RbohB and RbohD transcription in wild-type, $c n g c 6$, rbohB/D, and $c n g c 6 / r b o h B / D$ seedlings. The experiments were repeated three times with similar results. Each data point represents the mean $\pm \mathrm{SD}(n=3)$. Asterisks indicate a significant difference relative to Col; ${ }^{\star \star \star} p<0.001$ (Student's $t$-test). (B) About 8 -day-old wild-type, chgc6, rbohB/D, and cngc6/rbohB/D seedlings grown at $22^{\circ} \mathrm{C}$ were exposed to $45^{\circ} \mathrm{C}(\mathrm{HS})$ or maintained at $22^{\circ} \mathrm{C}(\mathrm{Control})$ for 30 min. The $\mathrm{H}_{2} \mathrm{O}_{2}$ levels in the seedlings were then examined by fluorescence microscopy using roots stained with $\mathrm{CM}-\mathrm{H}_{2} \mathrm{DCFDA}$. Bar $=100 \mu \mathrm{m}$. (C) Relative DCF fluorescence densities in the roots. The data presented are the means \pm SE of measurements taken from five independent experiments with at least 10 roots for each treatment. ${ }^{*} p<0.05$, and ${ }^{* *} p<0.01$ vs. $\mathrm{Col}$ (Student's $t$-test). (D) About 8-day-old seedlings grown at $22^{\circ} \mathrm{C}$ were exposed to $45^{\circ} \mathrm{C}(\mathrm{HS})$ or maintained at $22^{\circ} \mathrm{C}(\mathrm{Control})$ for 100 min, then returned to $22^{\circ} \mathrm{C}$ and photographed 5 days later. The clusters are as follows: 1 , wild-type; 2, cngc6; 3, rbohB/D; and 4, cngc6/rbohB/D. (E) Survival ratios of the seedlings after HS treatment. The data presented are the means \pm SE of at least five independent experiments with 50 seedlings per experiment. ${ }^{*} p<0.05$ and ${ }^{* \star} p<0.01$ vs. Col (Student's t-test).

crucial roles in the response of plant to HS (Liu et al., 2005; Sun and Guo, 2016). However, the relationship between $\mathrm{H}_{2} \mathrm{O}_{2}$ and $\mathrm{Ca}^{2+}$ signaling pathways in thermotolerance is unclear. Herein, our work showed that CNGC6, a heat-activated $\mathrm{Ca}^{2+}$ permeable channel, stimulates $\mathrm{H}_{2} \mathrm{O}_{2}$ accumulation to regulate the gene expression of Hsfs and HSPs accumulation to promote plant heat tolerance.

Hydrogen peroxide, an essential second messenger in a wide variety of biological processes, is stimulated by various factors to counteract exogenous stresses in plants. We previously reported that $\mathrm{H}_{2} \mathrm{O}_{2}$ acts as a signal in the induction of heat tolerance through NO (Wang et al., 2014). NO was even found to be associated with elevating intracellular levels of free $\mathrm{Ca}^{2+}$ under HS conditions (Peng et al., 2019). Recently, several studies have focused on the function of $\mathrm{Ca}^{2+}$ in initiating $\mathrm{H}_{2} \mathrm{O}_{2}$ accumulation in plants (Ferreira et al., 2003; Zhao et al., 2011).
Therefore, we speculated that there should be a close relationship between $\mathrm{Ca}^{2+}$ and $\mathrm{H}_{2} \mathrm{O}_{2}$ in $\mathrm{HS}$ signaling pathway.

In plants, the CNGC proteins are expressed differentially in numerous tissues (Zelman et al., 2012). Molecular genetic studies have revealed that CNGCs frequently function in numerous biological processes, including plant growth and development, adaptations to increased $\mathrm{Ca}^{2+}$ concentration, and plant responses to abiotic and biotic stresses (Gao et al., 2016; Jha et al., 2016). Our prior work has demonstrated that AtCNGC6 is a heat-activated $\mathrm{PM} \mathrm{Ca}{ }^{2+}$-permeable channel that conducts $\mathrm{Ca}^{2+}$ into the cytoplasm to help regulate $\mathrm{HS}$ responses. A T-DNA insertion mutant cncg6 was used for those investigations due to its lower $\mathrm{Ca}^{2+}$ current than the wild-type, which is nearly totally restored in the transgenic line COM12 plants after HS treatment (Gao et al., 2012; Peng et al., 2019), indicating that CNGC6 regulates the influx of $\mathrm{Ca}^{2+}$ into plant cells. 
A

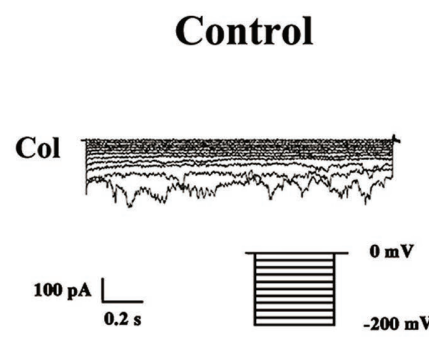

cngc6
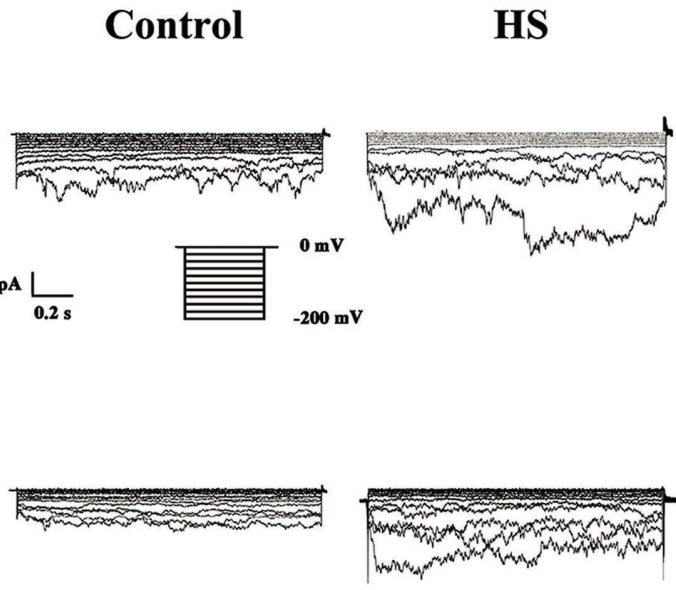

B

C

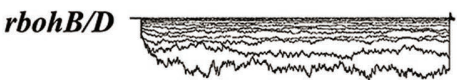

I- $V$ curve

Voltage (mV)

$-200-150-100-50$
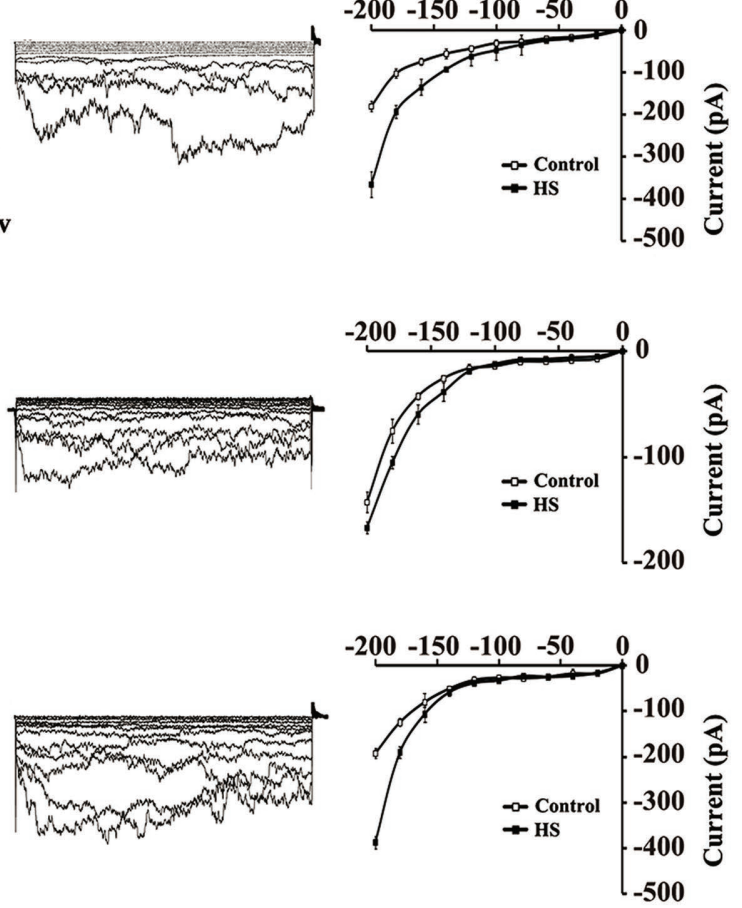

D

cngc6/rbohB/D

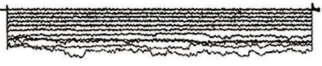

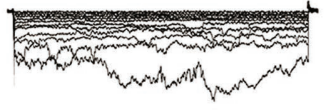

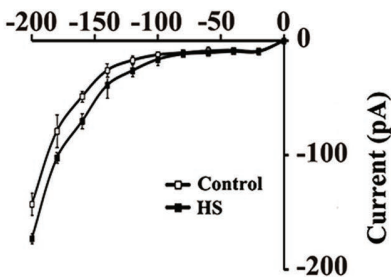

E

cngc6/35S::RbohB-1
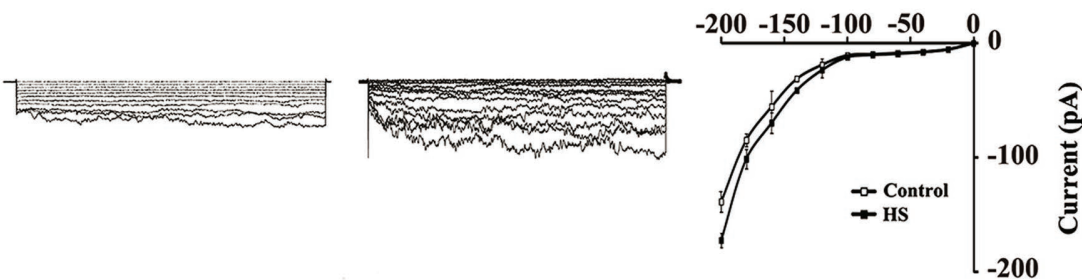

F

cngc6/35S::RbohD-1
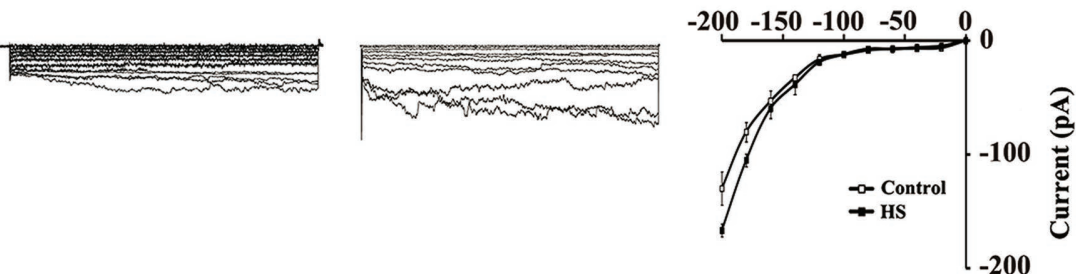

FIGURE 6 | Patch-clamp analysis of $\mathrm{Ca}^{2+}$-permeable channels in wild-type, cngc6, rbohB/D, cngc6/rbohB/D, cngc6/35S::RbohB-1, and cngc6/35S::RbohD-1 seedlings. The $\mathrm{Ca}^{2+}$ current before $\mathrm{HS}$ (at $22^{\circ} \mathrm{C}$, control) and after $\mathrm{HS}$ (at $37^{\circ} \mathrm{C}, \mathrm{HS}$ ) was compared in the root cell protoplasts of 8-day-old wild-type (A), cngc6 (B), rbohB/D (C), cngc6/rbohB/D (D), cngc6/35S::RbohB-1 (E), and cngc6/35S::RbohD-1 (F) plants. The Ca ${ }^{2+}$ current was recorded by step voltage clamp. Each trace is a representative current from six protoplasts. Currents in the protoplasts are shown in the left and middle columns, respectively. The $I-V$ curve is shown in the right column (mean $\pm \mathrm{SD}, n=6)$. 

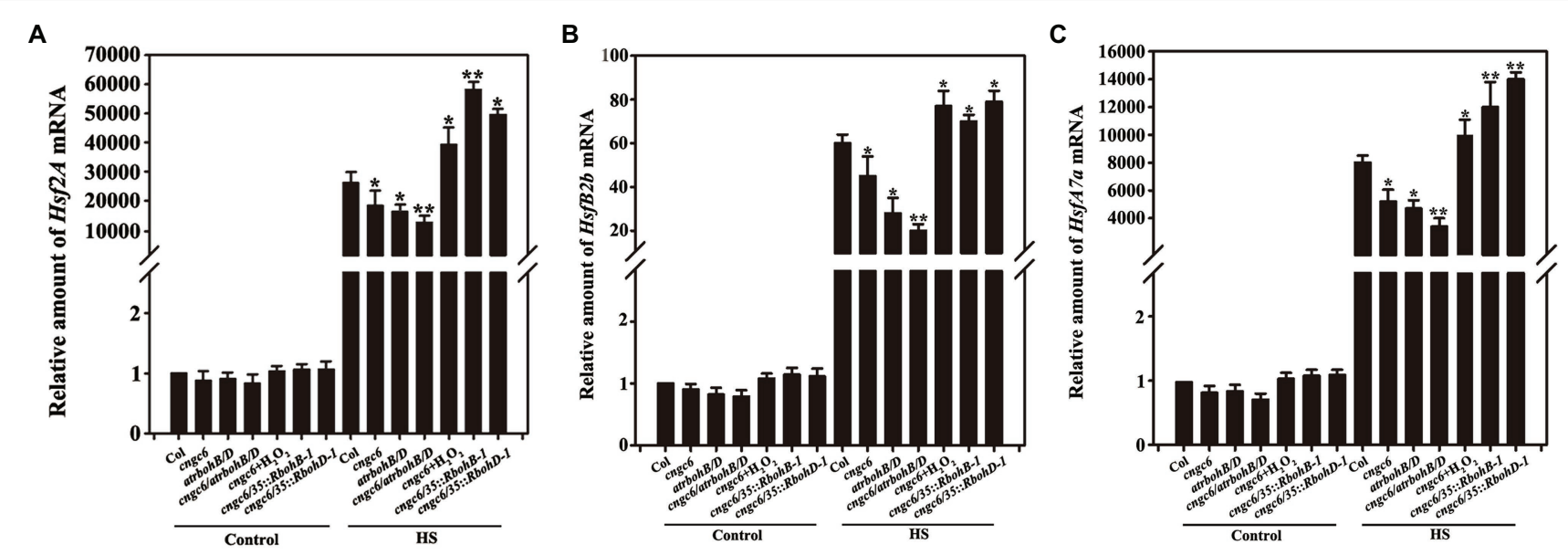

FIGURE 7 | Analysis of the effects of $\mathrm{CNGC6}$ on $\mathrm{H}_{2} \mathrm{O}_{2}$-induced $\mathrm{Hsfs}$ by RT-qPCR. About 10-day-old seedlings grown at $22^{\circ} \mathrm{C}$ was exposed to $37^{\circ} \mathrm{C}(\mathrm{HS})$ or maintained at $22^{\circ} \mathrm{C}$ (Control) for $60 \mathrm{~min}$, then used for analysis of Hsf (A, Hsf2A; B, HsfA7a; and C, HsfB2b) mRNA expression. The data are the mean \pm SE of at least five independent experiments. ${ }^{*} p<0.05$ and ${ }^{* *} p<0.01$ vs. Col (Student's $t$-test).

A

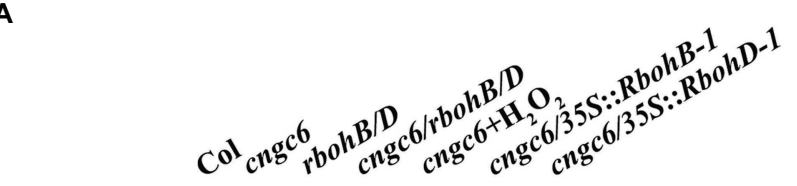

AtHSP17.7

Tubulin

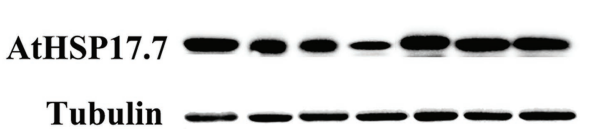

HS

C

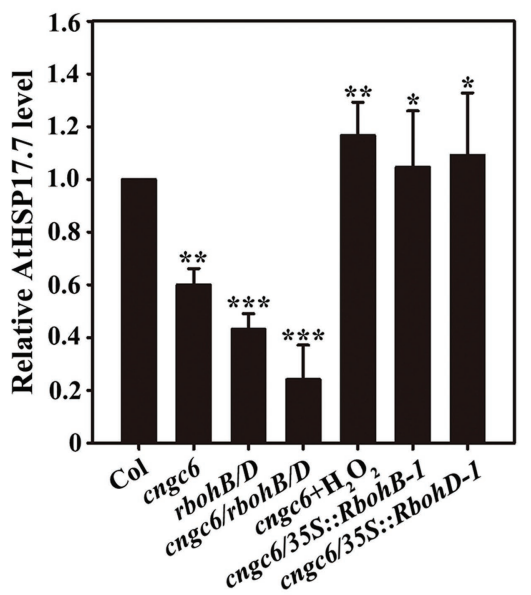

B

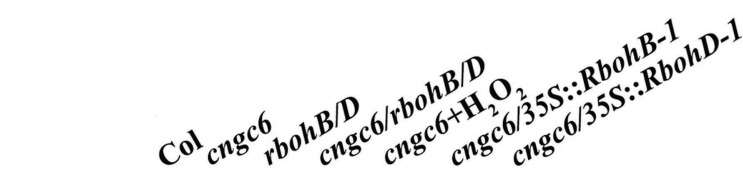

AtHSP21

Tubulin - - - - - -

Control

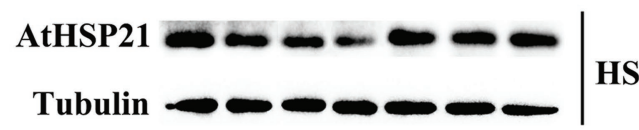

D

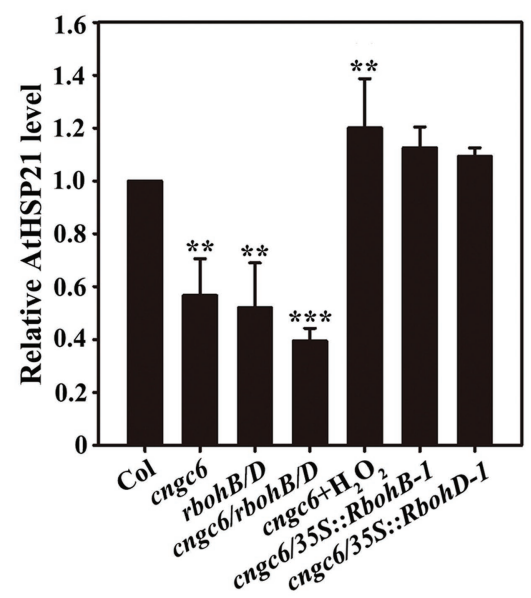

FIGURE 8 | Effects of CNGC6 via $\mathrm{H}_{2} \mathrm{O}_{2}$ on AtHSP17.7 and AtHSP21 expression. (A,B) About 10-day-old seedlings grown at $22^{\circ} \mathrm{C}$ were exposed to $37^{\circ} \mathrm{C}(\mathrm{HS})$ or maintained at $22^{\circ} \mathrm{C}$ (Control) for $2 \mathrm{~h}$. Total protein was then extracted, separated by SDS-PAGE, and analyzed by Western blotting. Tubulin was used as an internal control. Three independent experiments were carried out; the results indicate similar trends in protein accumulation. (C,D) The relative HSP17.7 (C) and HSP21 (D) level after HS treatment. The data presented are the means \pm SE of measurements taken from three independent experiments and represents the relative intensity of each signal. ${ }^{*} p<0.05,{ }^{* *} p<0.01$, and ${ }^{{ }^{* *}} p<0.001$ vs. Col (Student's $t$-test). 
Thus, we used the cngc6 mutant and the COM12 plants to examine the relationship between $\mathrm{H}_{2} \mathrm{O}_{2}$ and CNGC6 in plant thermotolerance.

The mRNA level of AtRbohB/D is stimulated by HS depending on CNGC6 expression levels (Supplementary Figure 1), indicating that CNGC6 regulates $\mathrm{H}_{2} \mathrm{O}_{2}$ accumulation under $\mathrm{HS}$ conditions. Thus, we first examined $\mathrm{H}_{2} \mathrm{O}_{2}$ levels using the fluorescent probe CM- $\mathrm{H}_{2}$ DCFDA. The results showed that high temperatures stimulated $\mathrm{H}_{2} \mathrm{O}_{2}$ accumulation according to their CNGC6 expression levels in the seedlings (Figures 1A,B), indicating an important role of CNGC6 in the regulation of $\mathrm{H}_{2} \mathrm{O}_{2}$ production in the $\mathrm{HS}$ pathway.

Because of the role of CNCG6 in conducting $\mathrm{Ca}^{2+}$ into the cytoplasm in HS-treated plants, we determined the effects of $\mathrm{Ca}^{2+}$ on $\mathrm{H}_{2} \mathrm{O}_{2}$ accumulations in the wild-type, $c n g c 6$, and COM12 seedlings. The results showed that $\mathrm{Ca}^{2+}$ increased $\mathrm{H}_{2} \mathrm{O}_{2}$ accumulation in the seedlings under high temperature, whereas the $\mathrm{Ca}^{2+}$ chelator EGTA clearly reduced $\mathrm{H}_{2} \mathrm{O}_{2}$ accumulations in the wild-type and COM12 seedlings (Figures 1C-H), indicating that CNGC6-mediated free $\mathrm{Ca}^{2+}$ is a crucial factor in promoting $\mathrm{H}_{2} \mathrm{O}_{2}$ signaling. Thus, we propose that CNGC6 participates in stimulating internal $\mathrm{H}_{2} \mathrm{O}_{2}$ levels via free $\mathrm{Ca}^{2+}$ in the HS pathway. However, EGTA had no clear effect on the $\mathrm{H}_{2} \mathrm{O}_{2}$ level in cngc6 seedlings, which might be due to the smaller increase in free $\mathrm{Ca}^{2+}$ under HS exposure (Figures 1E,F).

\section{Effects of $\mathrm{CNGC6}$ and $\mathrm{H}_{2} \mathrm{O}_{2}$ on Heat Tolerance in Arabidopsis Seedlings}

To interpret the effects of CNGC6 and $\mathrm{H}_{2} \mathrm{O}_{2}$ on thermotolerance, we determined the effects of $\mathrm{H}_{2} \mathrm{O}_{2}$ on the survival of wildtype and $c n g c 6$ seedlings exposed to HS conditions. Exogenous applications of $\mathrm{H}_{2} \mathrm{O}_{2}$ enhanced the internal $\mathrm{H}_{2} \mathrm{O}_{2}$ levels and the survival ratios of both of HS-treated wild-type and cngc6 seedlings (Figure 2). The overexpression of two HS-responsive $\mathrm{H}_{2} \mathrm{O}_{2}$ synthesis-related enzymes, RbohB and RbohD, simultaneously elevated the internal $\mathrm{H}_{2} \mathrm{O}_{2}$ levels and the survival ratios of these transgenic lines, in comparison with their non-transgenic background cngc6 under HS conditions (Figures 3, 4), respectively, indicating that an increase in internal $\mathrm{H}_{2} \mathrm{O}_{2}$ restored the heat sensitivity of the mutant plants because of the absence of CNGC6. We also identified a strange phenomenon in that a high $\mathrm{H}_{2} \mathrm{O}_{2}$ concentration $(200 \mu \mathrm{M})$ could not produce a high internal $\mathrm{H}_{2} \mathrm{O}_{2}$ level under $\mathrm{HS}$ conditions (Figures 2A,B), which is likely due to plant selfprotection against oxidative damage as discussed previously (Wang et al., 2014; Wu et al., 2015).

Next, we obtained the triple mutant $c n g c 6 / r b o h B / D$, which showed a phenotype similar to that of the $r b o h B / D$ double mutant under normal and HS conditions (Figure 5), revealing that deficiencies in CNGC6 and $R b o h B / D$ do not aggravate the heat susceptibility due to a deficiency in $R b o h B / D$.

Collectively, the upon results provide physiological and genetic proof for the existence of a novel HS signaling pathway in which CNGC6 is activated by high temperatures to mediate $\mathrm{H}_{2} \mathrm{O}_{2}$ accumulation to confer plant thermotolerance.

\section{Effects of $\mathrm{H}_{2} \mathrm{O}_{2}$ on $\mathrm{Ca}^{2+}$ Fluxes in the Responses of Arabidopsis Seedlings to HS Stress}

Hydrogen peroxide is the especially stable one of ROS and regulates plant growth, development, and stress adaptations. It acts through increasing $\left[\mathrm{Ca}^{2+}\right]_{c y t}$ as a second messenger, by the activation of the $\mathrm{PM} \mathrm{Ca}^{2+}$-permeable influx channels as a primary part of this process (Ordoñez et al., 2014; Richards et al., 2014; Shabala, 2019). However, only few studies have drawn the opposite conclusion that $\mathrm{Ca}^{2+}$ influx influences $\mathrm{H}_{2} \mathrm{O}_{2}$ generation. For example, the silencing of two tomato $\mathrm{CNGC}$ genes, SICNGC1 and SICNGC14, was reported to strikingly promote both pathogen-induced and flg22-elicited $\mathrm{H}_{2} \mathrm{O}_{2}$, revealing that two SICNGCs inhibit ROS production and attenuate non-host resistance and PAMP-triggered immunity (Zhang et al., 2018). Accordingly, we wondered whether $\mathrm{H}_{2} \mathrm{O}_{2}$ stimulates $\mathrm{Ca}^{2+}$ influxes to confer thermotolerance.

A marked elevation in $\mathrm{Ca}^{2+}$ current was presented in the response to a swift temperature increase from 22 to $37^{\circ} \mathrm{C}$ in the wild-type. However, the current was clearly inhibited in $\quad$ cngc6, cngc6/rbohB/D, cngc6/35S::RbohB-1, and cngc6/35S::RbohD-1 plants but not obviously varied in $r b o h B / D$ plants (Figure 6), showing no great effect of $\mathrm{H}_{2} \mathrm{O}_{2}$ on the activity of $\mathrm{Ca}^{2+}$-permeable channel. These results, in combination with those shown in Figures 2-5, proposed that the HS-induced alteration in $\mathrm{Ca}^{2+}$ unidirectionally stimulates $\mathrm{H}_{2} \mathrm{O}_{2}$ signaling in plants. A plausible interpretation for these data is that supplementation with $\mathrm{H}_{2} \mathrm{O}_{2}$, a downstream signal molecule, rescued the heat-susceptible phenotype of the CNGC6-deficient seedlings (Figures 2-5) but could not elevate the heat-responsive activity of CNGC6 (Figure 6).

\section{The Mechanism Underlying the Effects of CNGC6 via $\mathrm{H}_{2} \mathrm{O}_{2}$ on Thermotolerance}

To examine the mechanisms by which CNGC6 influences heat tolerance via $\mathrm{H}_{2} \mathrm{O}_{2}$, we determined the effects of CNGC6 and $\mathrm{H}_{2} \mathrm{O}_{2}$ on $\mathrm{Hsf}$ transcript and HSP expression under HS conditions.

Heat shock factors are known as downstream elements in the HS signaling pathway to regulate heat tolerance by deciding the expression of HSPs as the response to phosphorylation (Kotak et al., 2007). Our current data indicated that a reduction in the level of CNGC6 prohibits the transcript levels of $H s f s$, whereas applications of $\mathrm{H}_{2} \mathrm{O}_{2}$ and overexpression of $R b o h B$ and $R b o h D$ elevates them in $c n g c 6$ plants (Figure 7). Therefore, $\mathrm{H}_{2} \mathrm{O}_{2}$ appears to restore the CNGC6 effects, thereby influencing the $H s f s$ transcription and inducing to thermotolerance.

Heat shock protein genes, stimulated by HSFs linking to promoter elements, are categorized depending on their molecular masses, for example, HSP110, HSP100, HSP90, HSP70, and small HSPs, which are the most important ones among them due to their irreplaceable role in plant tolerance against high temperatures (Carre et al., 2019). To interpret the relationship between CNGC6 and $\mathrm{H}_{2} \mathrm{O}_{2}$ in the HS signaling pathway, we used HSP21 and HSP17.7, two small HSPs, to examine how CNGC6 mediates thermotolerance through $\mathrm{H}_{2} \mathrm{O}_{2}$. Western-blot analysis revealed that the reduced $C N G C 6$ level in $c n g c 6$ mutant decreased 
HSP21 and HSP17.7 expression under HS conditions, whereas application of $\mathrm{H}_{2} \mathrm{O}_{2}$ and the overexpression of RbohB or RbohD in cngc6 plants increased the accumulation of HSP21 and HSP17.7 (Figure 8), indicating that CNGC6 activated HSP expression via $\mathrm{H}_{2} \mathrm{O}_{2}$. Taken together, the mechanism through which CNGC6 influences thermotolerance via $\mathrm{H}_{2} \mathrm{O}_{2}$ involves variations in HSP gene expression.

These upon results suggest that CNGC6, the HS-responsive $\mathrm{Ca}^{2+}$-permeable channel, takes part in the initiation of HS signaling transduction through $\mathrm{H}_{2} \mathrm{O}_{2}$. We previously suggested a model for the HS signaling pathway in which the $\mathrm{HS}$ signal was received by an unknown receptor, resulting in an elevated $\mathrm{H}_{2} \mathrm{O}_{2}$ level and then stimulating $\mathrm{NO}$ production and AtCaM3 expression to initiate plant resistance against high temperatures (Xuan et al., 2010; Wang et al., 2014). Additionally, feedback inhibition existed between $\mathrm{NO}$ and $\mathrm{H}_{2} \mathrm{O}_{2}$ in the $\mathrm{HS}$ signaling pathway in Arabidopsis (Wu et al., 2015). AtCaM3 also inhibited excess $\mathrm{NO}$ accumulation and enhanced plant thermotolerance through stimulating $S$-nitrosoglutathione reductase by direct binding (Zhang et al., 2020). Recently, we found that CNGC6 through free $\mathrm{Ca}^{2+}$ acts upstream of NO in plant response to HS (Peng et al., 2019). In this work, CNGC6 was also proposed to act upstream of $\mathrm{H}_{2} \mathrm{O}_{2}$ through free $\mathrm{Ca}^{2+}$ in the HS pathway. $\mathrm{Ca}^{2+}$ and AtCaM3 are associated with HSP gene expression in Arabidopsis (Zhang et al., 2009). CaM, upon binding to $\mathrm{Ca}^{2+}$, attaches to specific targets, increasing their functions as part of a HS-responsive $\mathrm{Ca}^{2+}$ signaling pathway, for instance, CaM-binding protein kinase 3 (Liu et al., 2008) and PP7 (Liu et al., 2007). Thus, these findings suggest that interactions exist among $\mathrm{Ca}^{2+}$ channels, $\mathrm{H}_{2} \mathrm{O}_{2}$, NO, and the $\mathrm{Ca}^{2+} / \mathrm{CaM}$-dependent target proteins to participate in regulating HSP expression in the HS pathway.

\section{ACCESSION NUMBERS}

Sequence data from this article can be found in GenBank/ EMBL under the following accession numbers: AtRbohB (At1G09090), AtRbohD (AT5G47910), CNGC6 (At2g23980), and Actin2 (At3g18780).

\section{REFERENCES}

Akerfelt, M., Morimoto, R. I., and Sistonen, L. (2010). Heat shock factors: integrators of cell stress, development and lifespan. Nat. Rev. Mol. Cell Biol. 11, 545-555. doi: 10.1038/nrm2938

Banti, V., Mafessoni, F., Loreti, E., Alpi, A., and Perata, P. (2010). The heatinducible transcription factor HsfA2 enhances anoxia tolerance in Arabidopsis. Plant Physiol. 152, 1471-1483. doi: 10.1104/pp.109.149815

Bradford, M. M. (1976). A rapid and sensitive method for the quantitation of microgram quantities of protein utilizing the principle of protein-dye binding. Anal. Biochem. 72, 248-254. doi: 10.1016/0003-2697(76)90527-3

Brost, C., Studtrucker, T., Reimann, R., Denninger, P., Czekalla, J., Krebs, M., et al. (2019). Multiple cyclic nucleotide-gated channels coordinate calcium oscillations and polar growth of root hairs. Plant J. 99, 910-923. doi: 10.1111/ tpj. 14371

Carre, S., Alberti, S., Benesch, J. L. P., Boelens, W., Buchner, J., Carver, J. A., et al. (2019). Small heat shock proteins: multifaceted proteins with important implications for life. Cell Stress Chaperones 24, 295-308. doi: 10.1007/ s12192-019-00979-z

\section{DATA AVAILABILITY STATEMENT}

The original contributions presented in the study are included in the article/Supplementary Material, further inquiries can be directed to the corresponding author.

\section{AUTHOR CONTRIBUTIONS}

$\mathrm{BL}$ and LZo conceived the project and designed the research. WW and JZ carried out the phenotypic observation, RT-qPCR analysis, Arabidopsis transgenic experiments, and Western blot analysis. WW and LA carried out the whole-cell voltage patchclamping. LZn and DW participated in the data analysis. LZo wrote the article with contributions from all authors and revised and proofread the manuscript. All authors contributed to the article and approved the submitted version.

\section{FUNDING}

This work was supported by the National Natural Science Foundation of China Grants 31770297 (to LZo) and 31770261 (to LZn).

\section{ACKNOWLEDGMENTS}

We thank Miguel Angel Torress (Universidad Politécnica de Madrid) for providing the seeds and Yan Guo (China Agriculture University) for providing the $p C A M B I A 1307-6 \times M y c$ vector used in this research.

\section{SUPPLEMENTARY MATERIAL}

The Supplementary Material for this article can be found online at: https://www.frontiersin.org/articles/10.3389/fpls.2021.708672/ full\#supplementary-material

Chaouch, S., Queval, G., and Noctor, G. (2012). AtRbohF is a crucial modulator of defence-associated metabolism and a key actor in the interplay between intracellular oxidative stress and pathogenesis responses in Arabidopsis. Plant J. 69, 613-627. doi: 10.1111/j.1365-313X.2011.04816.x

Chozinski, T. J., Halpern, A. R., Okawa, H., Kim, H. J., Tremel, G. J., Wong, R. O. L., et al. (2016). Expansion microscopy with conventional antibodies and fluorescent proteins. Nat. Methods 13, 485-488. doi: 10.1038/ nmeth.3833

Clough, S. J., and Bent, A. F. (1998). Floral dip: a simplified method for agrobacterium-mediated transformation of Arabidopsis thaliana. Plant J. 16, 735-743. doi: 10.1046/j.1365-313x.1998.00343.x

Cui, Y., Lu, S., Li, Z., Cheng, J., Hu, P., Zhu, T., et al. (2020). Cyclic nucleotidegated ion channels 14 and 16 promote tolerance to heat and chilling in rice. Plant Physiol. 183, 1794-1808. doi: 10.1104/pp.20.00591

Demidchik, V., and Tester, M. (2002). Sodium fluxes through nonselective cation channels in the PM of protoplasts from Arabidopsis roots. Plant Physiol. 128, 379-387. doi: 10.1104/pp.010524

Ferreira, A. C., de Carvalho Cardoso, L., Rosenthal, D., and de Carvalho, D. P. (2003). Share thyroid $\mathrm{Ca}^{2+} / \mathrm{NADPH}$-dependent $\mathrm{H}_{2} \mathrm{O}_{2}$ generation is partially 
inhibited by propylthiouracil and methimazole. Eur. J. Biochem. 270, 2363-2368. doi: $10.1046 / j .1432-1033.2003 .03576 . x$

Gao, Q. F., Gua, L. L., Wang, H. Q., Fei, C. F., Fang, X., Hussain, J., et al. (2016). Cyclic nucleotide-gated channel 18 is an essential $\mathrm{Ca}^{2+}$ channel in pollen tube tips for pollen tube guidance to ovules in Arabidopsis. Proc. Natl. Acad. Sci. U. S. A. 113, 3096-3101. doi: 10.1073/pnas.1524629113

Gao, F., Han, X., Wu, J., Zheng, S., Shang, Z., Sun, D., et al. (2012). A heatactivated calcium-permeable channel-Arabidopsis cyclic nucleotide-gated ion channel 6-is involved in heat shock responses. Plant J. 70, 1056-1069. doi: 10.1111/j.1365-313X.2012.04969.x

Gechev, T. S., and Hille, J. (2005). Hydrogen peroxide as a signal controlling plant programmed cell death. J. Cell Biol. 168, 17-20. doi: 10.1083/jcb.200409170

Gupta, D. K., Pena, L. B., Romero-Puertas, M. C., Hernández, A., Inouhe, M., and Sandalio, L. M. (2017). NADPH oxidases differentially regulate ROS metabolism and nutrient uptake under cadmium toxicity. Plant Cell Environ. 40, 509-527. doi: 10.1111/pce.12711

Islam, M. M., Ye, W., Matsushima, D., Rhaman, M. S., Munemasa, S., Okuma, E., et al. (2019). Reactive carbonyl species function as signal mediators downstream of $\mathrm{H}_{2} \mathrm{O}_{2}$ production and regulate $\left[\mathrm{Ca}^{2+}\right]_{c y t}$ elevation in ABA signal pathway in Arabidopsis guard cells. Plant Cell Physiol. 60, 1146-1159. doi: 10.1093/pcp/pcz031

Iwai, S., Ogata, S., Yamada, N., Onjo, M., Sonoike, K., and Shimazaki, K. (2019). Guard cell photosynthesis is crucial in abscisic acid-induced stomatal closure. Plant Direct 3:e00137. doi: 10.1002/pld3.137

Jha, S. K., Sharma, M., and Pandey, G. K. (2016). Role of cyclic nucleotide gated channels in stress management in plants. Curr. Genomics 17, 315-329. doi: 10.2174/1389202917666160331202125

Jiang, Z., Zhu, S., Ye, R., Xue, Y., Chen, A., An, L., et al. (2013). Relationship between $\mathrm{NaCl}$ - and $\mathrm{H}_{2} \mathrm{O}_{2}$-induced cytosolic $\mathrm{Ca}^{2+}$ increases in response to stress in Arabidopsis. PLoS One 8:e76130. doi: 10.1371/journal.pone.0076130

Königshofer, H., Tromballa, H. W., and Löppert, H. G. (2008). Early events in signalling high-temperature stress in tobacco BY2 cells involve alterations in membrane flfluidity and enhanced hydrogen peroxide production. Plant Cell Environ. 31, 1771-1780. doi: 10.1111/j.1365-3040.2008.01880.x

Kotak, S., Larkindale, J., Lee, U., von Koskull-Döring, P., Vierling, E., and Scharf, K. D. (2007). Complexity of the heat stress response in plants. Curr. Opin. Plant Biol. 10, 310-316. doi: 10.1016/j.pbi.2007.04.011

Larkindale, J., Hall, J. D., Knight, M. R., and Vierling, E. (2005). Heat stress phenotypes of Arabidopsis mutants implicate multiple signaling pathways in the acquisition of thermotolerance. Plant Physiol. 138, 882-897. doi: 10.1104/pp.105.062257

Lawas, L. M. F., Zuther, E., Jagadish, S. V. K., and Hincha, D. K. (2018). Molecular mechanism of combined heat and drought stress resilience in cereals. Curr. Opin. Plant Biol. 45, 212-217. doi: 10.1016/j.pbi.2018.04.002

Lewis, A. M., Matzdorf, S. S., and Rice, K. C. (2016). Fluorescent detection of intracellular nitric oxide in Staphylococcus aureus. Bio Protoc. 6:e1878. doi: 10.21769/BioProtoc. 1878

Li, N., Sun, L., Zhang, L., Song, Y., Hu, P., Li, C., et al. (2015). AtrbohD and AtrbohF negatively regulate lateral root development by changing the localized accumulation of superoxide in primary roots of Arabidopsis. Planta 241, 591-602. doi: 10.1007/s00425-014-2204-1

Liu, H. T., Gao, F., Li, G. L., Han, J. L., Liu, D. L., Sun, D. Y., et al. (2008). The calmodulin-binding protein kinase 3 is part of heat-shock signal transduction in Arabidopsis thaliana. Plant J. 55, 760-773. doi: 10.1111/j.1365-313X.2008.03544.x

Liu, H. T., Li, G. L., Chang, H., Sun, D. Y., Zhou, R. G., and Li, B. (2007). Calmodulin binding protein phosphatase PP7 is involved in thermotolerance in Arabidopsis. Plant Cell Environ. 30, 156-164. doi: 10.1111/j.1365-3040.2006.01613.x

Liu, H. T., Sun, D. Y., and Zhou, R. G. (2005). $\mathrm{Ca}^{2+}$ and AtCaM3 are involved in the expression of heat shock protein gene in Arabidopsis. Plant Cell Environ. 28, 1276-1284. doi: 10.1111/j.1365-3040.2005.01365.x

Macpherson, N., Takeda, S., Shang, Z., Dark, A., Mortimer, J. C., Brownlee, C., et al. (2008). NADPH oxidase involvement in cellular integrity. Planta 227, 1415-1418. doi: 10.1007/s00425-008-0716-2

Maruta, T., Inoue, T., Tamoi, M., Yabuta, Y., Yoshimura, K., Ishikawa, T., et al. (2011). Arabidopsis NADPH oxidases, AtrbohD and AtrbohF, are essential for jasmonic acid-induced expression of genes regulated by MYC2 transcription factor. Plant Sci. 180, 665-660. doi: 10.1016/j.plantsci.2011.01.014

Nazir, F, Fariduddin, Q., and Khan, T. A. (2020). Hydrogen peroxide as a signalling molecule in plants and its crosstalk with other plant growth regulators under heavy metal stress. Chemosphere 252:126486. doi: 10.1016/j. chemosphere.2020.126486

Niu, W. T., Han, X. W., Wei, S. S., Shang, Z. L., Wang, J., Yang, S. W., et al. (2020). Arabidopsis cyclic nucleotide-gated channel 6 is negatively modulated by multiple calmodulin isoforms during heat shock. J. Exp. Bot. 71, 90-104. doi: $10.1093 / \mathrm{jxb} / \mathrm{erz} 445$

Ordoñez, N. M., Marondedze, C., Thomas, L., Pasqualini, S., Shabala, L., Shabala, S., et al. (2014). Cyclic mononucleotides modulate potassium and calcium flux responses to $\mathrm{H}_{2} \mathrm{O}_{2}$ in Arabidopsis roots. FEBS Lett. 588, 1008-1015. doi: 10.1016/j.febslet.2014.01.062

Pan, Y., Chai, X., Gao, Q., Zhou, L., Zhang, S., Li, L., et al. (2019). Dynamic interactions of plant CNGC subunits and calmodulins drive oscillatory $\mathrm{Ca}^{2+}$ channel activities. Dev. Cell 48, 710-725. doi: 10.1016/j.devcel.2018.12.025

Peng, X., Zhang, X., Li, B., and Zhao, L. (2019). Cyclic nucleotide-gated ion channel 6 mediates thermotolerance in Arabidopsis seedlings by regulating nitric oxide production via cytosolic calcium ions. BMC Plant Biol. 19:368 doi: 10.1186/s12870-019-1974-9

Richards, S. L., Laohavisit, A., Mortimer, J. C., Shabala, L., Swarbreck, S. M., Shabala, S., et al. (2014). Annexin 1 regulates the $\mathrm{H}_{2} \mathrm{O}_{2}$-induced calcium signature in Arabidopsis thaliana roots. Plant J. 77, 136-145. doi: 10.1111/ tpj. 12372

Shabala, S. (2019). Linking ploidy level with salinity tolerance: NADPH-dependent 'ROS-Ca ${ }^{2+}$ hub' in the spotlight. J. Exp. Bot. 70, 1063-1067. doi: 10.1093/ jxb/erz042

Sun, A. Z., and Guo, F. Q. (2016). Chloroplast retrograde regulation of heat stress responses in plants. Front. Plant Sci. 7:398. doi: 10.3389/fpls.2016.00398

Talke, I. N., Blaudez, D., Maathuis, F. J., and Sanders, D. (2003). CNGCs: prime targets of plant cyclic nucleotide signalling? Trends Plant Sci. 8, 286-293. doi: 10.1016/S1360-1385(03)00099-2

Tian, W., Hou, C., Ren, Z., Wang, C., Zhao, F., Dahlbeck, D., et al. (2019). A calmodulin-gated calcium channel links pathogen patterns to plant immunity. Nature 572, 131-135. doi: 10.1038/s41586-019-1413-y

Walker, R. K., and Berkowitz, G. A. (2013). Detection of reactive oxygen species downstream of cyclic nucleotide signals in plants. Methods Mol. Biol. 1016, 245-252. doi: 10.1007/978-1-62703-441-8_17

Wang, L., Guo, Y., Jia, L., Chu, H., Zhou, S., Chen, K., et al. (2014). Hydrogen peroxide acts upstream of nitric oxide in the heat shock pathway in Arabidopsis seedlings. Plant Physiol. 164, 2184-2196. doi: 10.1104/pp.113.229369

Wang, J., Liu, X., Zhang, A., Ren, Y., Wu, F., Wang, G., et al. (2019). A cyclic nucleotide-gated channel mediates cytoplasmic calcium elevation and disease resistance in rice. Cell Res. 29, 820-831. doi: 10.1038/s41422-019-0219-7

Wang, Y., Ries, A., Wu, K., Yang, A., and Crawford, N. M. (2010). The Arabidopsis prohibition gene $P H B 3$ functions in nitric oxide-mediated responses and in hydrogen peroxide-induced nitric oxide accumulation. Plant Cell 22, 249-259. doi: $10.1105 /$ tpc. 109.072066

Wu, D., Chu, H., Jia, L., Chen, K., and Zhao, L. (2015). A feedback inhibition between nitic oxide and hydrogen peroxide in the heat shock pathway in Arabidopsis seedlings. Plant Growth Regul. 75, 503-509. doi: 10.1007/ s10725-014-0014-x

Xuan, Y., Zhou, S., Wang, L., Cheng, Y., and Zhao, L. (2010). Nitric oxide functions as a signal and acts upstream of AtCaM3 in thermotolerance in Arabidopsis seedlings. Plant Physiol. 153, 1895-1906. doi: 10.1104/pp.110.160424

Zelman, A. K., Dawe, A., Gehring, C., and Berkowitz, G. A. (2012). Evolutionary and structural perspectives of plant cyclic nucleotide-gated cation channels. Front. Plant Sci. 3:95. doi: 10.3389/fpls.2012.00095

Zhang, X., Wang, W., Kang, X., and Zhao, L. (2020). Arabidopsis CaM3 inhibits nitric oxide accumulation and improves thermotolerance by promoting $S$ nitrosoglutathione reductase via direct binding. Plant Growth Regul. 90, 41-50. doi: $10.1007 / \mathrm{s} 10725-019-00552-9$

Zhang, X. R., Xu, Y. P., and Cai, X. Z. (2018). SICNGC1 and SICNGC14 suppress Xanthomonas oryzae pv. Oryzicola-induced hypersensitive response and non-host resistance in tomato. Front. Plant Sci. 9:285. doi: 10.3389/ fpls.2018.00285

Zhang, W., Zhou, R. G., Gao, Y. J., Zheng, S. Z., Xu, P., Zhang, S. Q., et al. (2009). Molecular and genetic evidence for the key role of AtCaM3 in heat-shock signal transduction in Arabidopsis. Plant Physiol. 149, 1773-1784. doi: $10.1104 /$ pp.108.133744

Zhao, X., Wang, Y. J., Wang, Y. L., Wang, X. L., and Zhang, X. (2011). Extracellular $\mathrm{Ca}^{2+}$ alleviates $\mathrm{NaCl}$-induced stomatal opening through a pathway 
involving $\mathrm{H}_{2} \mathrm{O}_{2}$-blocked $\mathrm{Na}^{+}$influx in Vicia guard cells. J. Plant Physiol. 168, 903-910. doi: 10.1016/j.jplph.2010.11.024

Conflict of Interest: The authors declare that the research was conducted in the absence of any commercial or financial relationships that could be construed as a potential conflict of interest.
Copyright () 2021 Wang, Zhang, Ai, Wu, Li, Zhang and Zhao. This is an open-access article distributed under the terms of the Creative Commons Attribution License (CC BY). The use, distribution or reproduction in other forums is permitted, provided the original author(s) and the copyright owner(s) are credited and that the original publication in this journal is cited, in accordance with accepted academic practice. No use, distribution or reproduction is permitted which does not comply with these terms. 